\title{
CONTENDIENDO EN LA GLOBALIZACIÓN. LOS EMPRESARIOS CAFETALEROS DEL SOCONUSCO Y LA ORgANizACión DE LAS CADENAS DE PRODUCCIÓN LOCALES Y GLOBALES
}

\author{
Contending in Globatization. Soconusco Coffee \\ ENTREPRENEURS AND THE Organization OF LOCAL AND \\ Global Production Chains
}

\author{
Manuel Iván Espinosa Gallegos* \\ Héctor B. Fletes Ocón** \\ Alessandro Bonanno**** \\ DOI: https://doi.org/10.31644/ED.V8.N1.2021.A01
}

\begin{abstract}
Resumen: Desde fines del siglo XIX, los empresarios cafetaleros de la región Soconusco en Chiapas, con el apoyo del Estado, establecieron vínculos de producción, transformación y distribución del producto con importadores y torrefactores estadounidenses y europeos. El propósito del artículo es examinar las estrategias y alianzas establecidas por estos empresarios, principalmente desde la década de 1990 del siglo XX, para hacer frente a la reestructuración de la industria cafetalera y el ascenso de las empresas transnacionales en el contexto de la globalización. Entre esas estrategias se encuentra la diversificación de las actividades empresariales, la especialización en el negocio del café y la revalorización del territorio y el agroecosistema. En la investigación se emplearon principalmente métodos cualitativos para recuperar las experiencias y perspectivas de los principales agentes que participan en las cadenas de producción —empresarios finqueros del café, distribuidores, torrefactores-, miembros de organizaciones cafetaleras y de entidades públicas de la región y del estado. La principal conclusión es que los empresarios cafetaleros conformaron un grupo con diferentes grados de alianzas y disputas con actores transnacionales para consolidar diversas formas de inserción en la industria mundial del café; de tal forma que la globalización no implicó un control directo del flujo de recursos y procesos en la cadena del café.
\end{abstract}

* Dr. en Estudios Regionales, director general de planeación de la Universidad Autónoma de Chiapas, México. ORCiD: https://orcid.org/0000-0002-1835-0485 Correo-e: $\underline{\text { ivan.espinosa@unach.mx. }}$

** Dr. en Ciencias Sociales, especialidad en Antropología Social, profesor de la Facultad de Ciencias Sociales de la Universidad Autónoma de Chiapas, México. ORCiD: https://orcid.org/0000-0001-5603-1808 Correo-e: hector.fletes@unach.mx.

*** Dr. en Sociología, profesor titular emeritus de sociología en la Sam Houston State University, Estados Unidos de América. ORCiD: https://orcid.org/0000-0003-2868-2798 Correo-e: SOC AAB@shsu.edu.

Fecha de recepción: 05/09/2020. Fecha de aceptación: 26/12/2020. Fecha de publicación: 30/01/2021.

(cc) BY-NC-ND

EntreDiversidades. Revista de Ciencias Sociales y Humanidades, vol. 8, núm. 1 (16), enero-junio 2021. Páginas: 6 - 35 ISSN-e: 2007-7610. https://doi.org/10.31644/ED.V8.N1.2021.A01 
Palabras clave: empresarios, globalización, cadenas de producción, café, Chiapas.

Abstract: Since the end of the nineteenth century and with State support, coffee entrepreneurs from the Soconusco region in Chiapas have formed production, transformation and distribution links with American and European importers and roasters. The purpose of this study is to examine the strategies and alliances that these entrepreneurs established to address the global restructuration of the coffee industry and the rise of transnational companies. These strategies include, among others, the diversification of business activities, specialization of coffee business and a revitalization of the territory and agroecosystem. Employing qualitative methods, the research underscores the experiences and perspectives of key actors participating in production chains — farmers entrepreneurs, distributors, roasters-, members of coffee grower organizations, and public entities of the region and the state. The article's primary conclusion affirms that coffee entrepreneurs were able to establish varying alliances, but also different degree of dissent, with transnational actors that enabled their insertion into the global coffee industry. Accordingly, globalization did not imply the development of a direct external control of the flow of resources and processes of the production chain.

Keywords: entrepreneurs, globalization, production chains, coffee, Chiapas.

\section{Introducción}

Las narrativas más comunes de la globalización — que señalan temas como la configuración de cadenas de producción global, la reconfiguración del papel del Estado o las tendencias de homogeneización de las formas de vida - en la actualidad se ven cuestionadas por los procesos de nacionalismo, proteccionismo y hasta el cierre de los flujos de mercancías y de personas debido a la presencia de nuevas enfermedades de circulación global (Amadeo, 2020). De tal manera, el mundo se presenta de un carácter convulso y los procesos demuestran una cualidad contingente. Paradójicamente, esto refuerza la importancia analítica del concepto de globalización, como una oportunidad para generar conocimiento histórico (Robinson, 2014a).

La región Soconusco de Chiapas se fundó sobre la base de la industria del café. Este factor la dotó, a finales del siglo XIX, de mayores conexiones con Europa que con el resto del país. En ese momento, la producción de café fue establecida por empresarios. Varios de ellos eran inmigrantes europeos que llegaron a México buscando fortuna, en algunos casos desde el vecino Guatemala, aprovechando condiciones que el Estado mexicano les otorgaba para la posesión y ocupación de tierra, y para la producción de una mercancía que era altamente demandada en sus países de origen (Espinosa, 2018).

Con el tiempo, los inmigrantes, empresarios cafetaleros y otros actores locales se insertaron en, y conformaron, cadenas de producción y distribución del café con importadores y torrefactores europeos. Estas relaciones sociales y comerciales, así como el conocimiento generado a través de varias generaciones, les permitió enfrentar las transformaciones de la industria cafetalera, asociadas con el desmantelamiento del Acuerdo Internacional del Café en los ańos noventa,

EntreDiversidades. Revista de Ciencias Sociales y Humanidades, vol. 8, núm. 1 (16), enero-junio 2021. Páginas: 6 - 35 ISSN-e: 2007-7610. https://doi.org/10.31644/ED.V8.N1.2021.A01 
que ocasionó reducciones drásticas de precios internacionales del café, la concentración de la industria y la rápida transformación de las regulaciones y estándares de aplicación internacional (Hernández, 2019). La participación de estos actores en la cadena global del café se logró mediante una diversidad de conocimientos y estrategias, así como de formas específicas de relación con torrefactores y distribuidores, que en ocasiones se orientaron hacia una diversificación de las actividades empresariales y, en otras, desplegaron una ultra-especialización en el negocio del café, o incluso condujeron a una revalorización de la tierra y el territorio. En el presente trabajo se examinan estas estrategias y alianzas establecidas por empresarios cafetaleros en la región del Soconusco en Chiapas, en las que predomina una situación de negociación por parte del empresario soconusquense frente a las empresas transnacionales.

El análisis histórico de la globalización enfocado en una región concreta es importante, primero porque desdibuja la aparente unidireccionalidad del cambio social prevaleciente en numerosos trabajos en los cuales se asume una relación de subordinación de los territorios respecto a las "fuerzas globales". En segundo lugar, porque el empresarial es un sector poco estudiado en esta región histórica cafetalera y en el estado de Chiapas, pues se ha puesto la atención (con mucha razón, debido al rezago socioeconómico) en grupos, sociedades o cooperativas de carácter social ${ }^{1}$.

El trabajo de campo se realizó fundamentalmente entre octubre de 2010 y agosto de 2012, en la región Soconusco, Chiapas. La investigación empleó principalmente métodos cualitativos como entrevistas a profundidad, semiestructuradas y observación participante, visitas a diez fincas cafetaleras y a seis oficinas de las empresas productoras y comercializadoras ${ }^{2}-$. Se conversó con dueños y trabajadores de las fincas, así como con representantes de empresas comercializadoras y exportadoras de café verde y tostado. En total, se realizaron 21 entrevistas para abarcar distintas etapas de las cadenas locales y globales de café, como producción, comercialización y torrefacción. También, se dialogó con personal de la Unión Agrícola Regional de Productores de Café Tacaná, la Comisión para el Desarrollo y Fomento del Café de Chiapas, la Secretaría de Agricultura, Ganadería y Desarrollo Rural, Pesca y Alimentación (SAGARPA) y una entidad financiera rural. La información presentada en este trabajo fue actualizada y validada mediante diálogos informales recientes con los sujetos entrevistados, consulta de páginas de internet de las empresas consideradas y de firmas con las que sostienen relaciones productivas y de comercio.

En el texto, se presenta primero el contexto histórico de la región Soconusco y su relación con el café. El segundo apartado se refiere a los principales debates sobre la globalización y las cadenas de producción; posteriormente, se analizan las estrategias y las articulaciones entre empresas transnacionales y los actores empresariales locales y regionales vinculados con la cadena

\footnotetext{
${ }^{1}$ Algunos trabajos recientes sobre este importante tema son los de Zamora, Pérez y Picazzo (2019); Quiroga (2019) y Sánchez (2016).

${ }^{2}$ Se realizaron visitas periódicas a los actores empresariales. Estos fueron identificados mediante la técnica de bola de nieve (Tashakkori y Teddlie, 2010). Es decir, a partir del primer contacto que se tuvo con un grupo de tres empresarios, se pidió referencias de otros con las mismas características; a saber, dueños de plantaciones mayores de 25 hectáreas de café arábiga en la región del Soconusco o empresarios comercializadores de cafés de especialidad. Cuando fue imposible lograr algunas entrevistas, se recuperó información mediante fuentes secundarias como literatura especializada, bases de datos, notas periodísticas, páginas electrónicas y redes sociales.
}

EntreDiversidades. Revista de Ciencias Sociales y Humanidades, vol. 8, núm. 1 (16), enero-junio 2021. Páginas: 6 - 35 ISSN-e: 2007-7610. https://doi.org/10.31644/ED.V8.N1.2021.A01 
del café, así como sus efectos en el territorio. Antes de las conclusiones, se presentan dos casos de empresarios locales que dan cuenta de la flexibilidad de sus estrategias en el entorno de reestructuración de la industria global.

\section{Soconusco y café}

El café fue introducido en Chiapas en 1846 por finqueros italianos y alemanes que se establecieron en la región del Soconusco (Venegas, et al., 2020: 10). La primera huerta fue establecida en la finca La Chácara por un italiano de nombre Jerónimo Manchinelli (o Manchinelly) con 1500 plantas de café Bourbon traídas del Departamento de Quezaltenango en la Costa Cuca de Guatemala (Helbig, 1964). De este modo, las primeras plantaciones de café en la región se establecieron a principios de la década de 1880, en el contexto de la promulgación de la Ley sobre las Compañías Deslindadoras en México (en 1875, por Sebastián Lerdo de Tejada) y el convenio firmado por el gobierno de Porfirio Díaz con la empresa Mexican Land and Colonization de San Francisco, con lo que grupos de estadounidenses, franceses y alemanes llegaron a probar suerte al Soconusco (Renard, 1993: 20). Contribuyó en ello, también, la delimitación de la frontera con Guatemala.

Inmigrantes y empresas alemanas, que habían comenzado previamente su actividad cafetalera en Guatemala, tenían varias razones para establecerse en el Soconusco. Además de la Ley mencionada, otros factores en este proceso fueron: la falta de disponibilidad de tierras en la Costa Cuca de aquel país, a donde habían llegado en los setenta del siglo dieciocho; la firma, en 1882, del Tratado de Límites que definió la frontera entre los dos países; el aumento del precio del café en el mercado internacional (ocasionado por la Revolución en Brasil) y la disminución de la cosecha en la Costa Cuca de Guatemala (Spenser, 1988; Renard, 1993). Esta expansión al sur de México les permitiría ampliar sus redes sociales y comerciales, desarrolladas en varios países de Centroamérica y que los vinculaba con el mercado europeo (Berth, 2018; Venegas, et al., 2020).

En Guatemala, también producían café empresarios franceses, belgas y los mismos guatemaltecos que ya tenían décadas de cultivarlo. Sin embargo, los alemanes contribuyeron en gran medida al desarrollo de la cafeticultura porque eran dueños o intermediarios de grandes capitales (Spenser, 1988). Algunos "eran comerciantes y banqueros en Hamburgo, con plantaciones de café en Guatemala, donde su dinero sirvió no sólo para ensanchar negocios propios sino para otorgar préstamos con intereses, a fin de que otros pudieran hacer lo mismo, aunque a menor escala" (Spenser, 1988: 71). Cuando llegaron los empresarios alemanes al Soconusco, a finales de los ochenta del siglo XIX, ya contaban con experiencia, tecnología, respaldo financiero y vínculos comerciales en los mercados internacionales para iniciar con éxito la colonización del Soconusco.

Como los empresarios alemanes ya disponían de un negocio próspero, su interés no solo era la producción del grano, sino servir de intermediarios entre otros cafeticultores y los mercados europeos y estadounidenses. A diferencia de los colonizadores, que debían buscar financiamiento para la producción de café entre comerciantes, usureros u otros finqueros, los primeros tenían ventajas debido al vasto financiamiento con que contaban, pues tenían acceso a capitales por medio de sus casas comerciales (Berth, 2018).

EntreDiversidades. Revista de Ciencias Sociales y Humanidades, vol. 8, núm. 1 (16), enero-junio 2021. Páginas: 6 - 35 ISSN-e: 2007-7610. https://doi.org/10.31644/ED.V8.N1.2021.A01 
Cabe señalar que los finqueros reprodujeron lo que ya era una institución en Guatemala, un sistema de peonaje basado en el endeudamiento y el contrato forzoso, consistente en reclutar a los indígenas desde sus comunidades para llevarlos a trabajar a las fincas cafetaleras con base en engaños, entregándoles anticipos en efectivo o bienes de consumo (incluso aguardiente) que nunca terminaban de pagar con su trabajo en las plantaciones de café (Renard, 1999: 29).

A pesar de esto, los finqueros tuvieron que enfrentar un problema de escasez de trabajadores, pues los indígenas de Los Altos "regresaban regularmente a sus lugares de origen para cultivar sus milpas y cumplir con sus obligaciones religiosas en sus comunidades" (Renard, 1993: 29). Esto contradecía la idea de los colonos de que las comunidades, al ser herméticamente organizadas (con costumbres, lenguas e indumentarias propias), estaban habitadas por gente primitiva, desocupada y sobre todo autónoma, de tal suerte que se necesitaba únicamente "sacar a los indígenas de sus espacios supuestamente aislados e introducirlos en la economía monetaria" para aprovechar toda su fuerza de trabajo (Rus, 2005: 256). En realidad, argumenta Rus, dichas comunidades eran manejadas por las élites mestizas locales, las cuales las tenían como reserva de mano de obra, de acuerdo con prácticas arraigadas desde el periodo colonial.

La Primera Guerra Mundial provocó dificultades en la comunicación con los mercados europeos y bloqueos de las rutas marítimas. Entonces, Estados Unidos se convirtió en el principal proveedor de capitales para inversión. Los dueños seguían siendo los alemanes, pero ahora con capitales estadounidenses, de modo que "Nueva York y Nueva Orleans reemplazaron a Hamburgo y Bremen como mercados de capitales" (Spenser, 1988: 120). Asimismo, el flujo comercial del café y otros bienes se amplió hacia Estados Unidos y disminuyó hacia Europa.

En ese sentido, el desarrollo de la cafeticultura en el Soconusco se había logrado en la medida que coincidieron dos iniciativas: la expansión capitalista del imperio alemán y el proyecto de desarrollo económico del gobierno de México, basado en la colonización para fomentar las actividades productivas, particularmente las enfocadas a la exportación. Se puede señalar que la llegada de estos empresarios inmigrantes dio continuidad a los hacendados, establecidos en la región desde la Colonia, aunque, a diferencia de estos, los finqueros implantaron un proceso de producción y comercialización del café totalmente capitalista (en el Mapa 1 se muestra la localización de las fincas cafetaleras en la región). 
Mapa 1. Localización de las fincas cafetaleras en el Soconusco, Chiapas

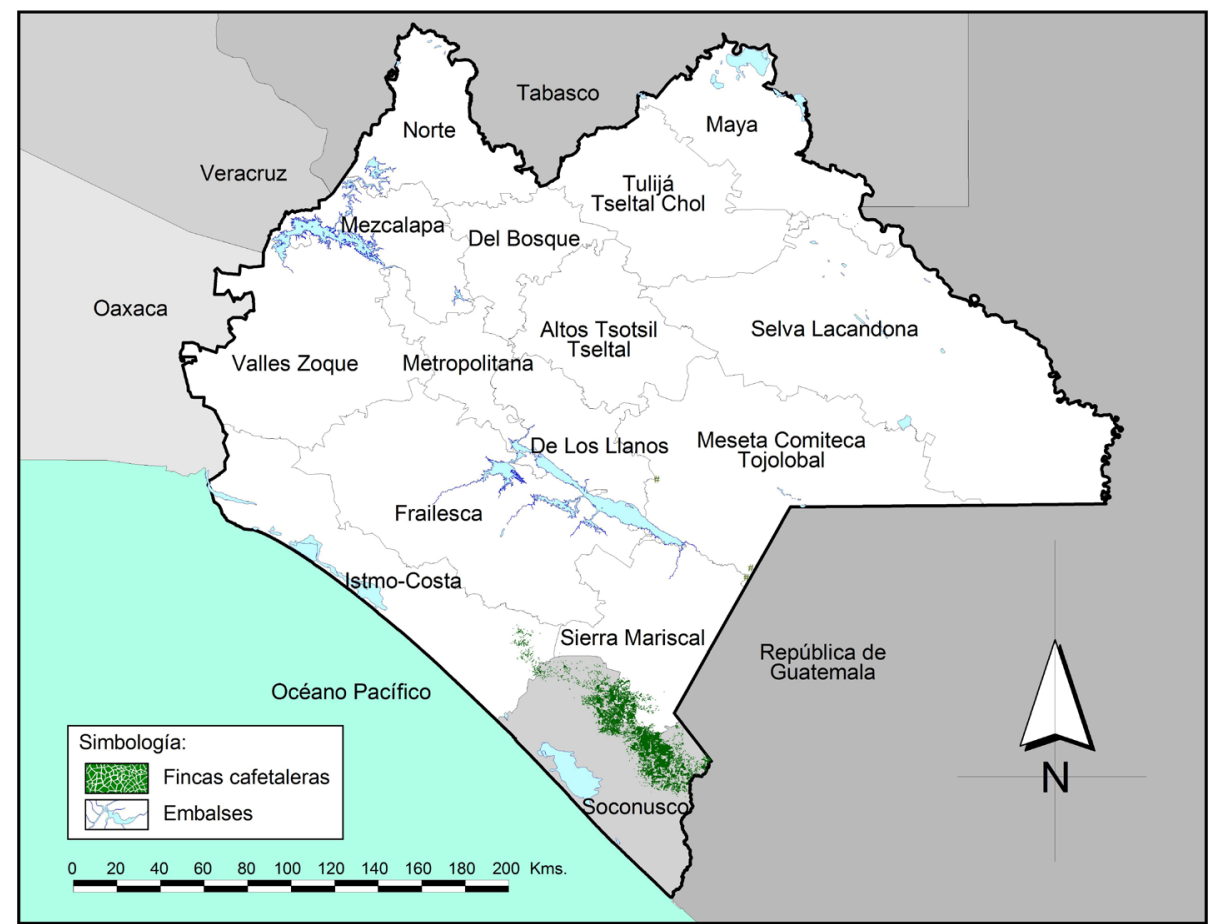

Fuente: Elaboración propia, por el Arq. Federico A. Stransky Paniagua, con información del Padrón Nacional Cafetalero de la Secretaría de Agricultura y Desarrollo Rural (SAGARPA), 2018.

En el Soconusco se llegaron a establecer 75 mil ha de café, esto es, alrededor de una tercera parte de la superficie del estado de Chiapas. No obstante, en la última década ha habido una fuerte caída tanto en la superficie sembrada como en los rendimientos de café cereza y esta caída es más intensa en la región Soconusco y en el municipio de Tapachula que en el estado. De las regiones cafetaleras de Chiapas, únicamente Sierra Mariscal y Altos Tsotsil Tseltal destacan por mantener rendimientos superiores a dos toneladas de café cereza por hectárea en las últimas dos décadas (ver Tabla 1). 
Tabla 1. Superficie sembrada, cosechada, volumen de producción y rendimiento de café cereza. Estado de Chiapas, principales regiones productoras y municipio de Tapachula (2003-2019)

\begin{tabular}{|c|c|c|c|c|c|}
\hline Lugar & Año & $\begin{array}{c}\text { Superficie } \\
\text { sembrada } \\
\text { (HA) }\end{array}$ & $\begin{array}{c}\text { Superficie } \\
\text { cosechada } \\
(\text { HA) }\end{array}$ & $\begin{array}{l}\text { Producción } \\
\text { (TON) }\end{array}$ & $\begin{array}{c}\text { Rendimiento } \\
\text { (TON/HA) }\end{array}$ \\
\hline \multirow{5}{*}{ Chiapas } & 2003 & 241.1 & 237.8 & 587.8 & 2.5 \\
\hline & 2007 & 254.0 & 252.0 & 565.7 & 2.2 \\
\hline & 2011 & 257.4 & 243.7 & 545.9 & 2.2 \\
\hline & 2015 & 261.6 & 245.3 & 383.1 & 1.6 \\
\hline & 2019 & 252.7 & 231.6 & 367.9 & 1.6 \\
\hline \multirow{5}{*}{$\begin{array}{l}\text { Altos Tsotsil } \\
\text { Tseltal }\end{array}$} & 2003 & 12.3 & 12.3 & 33.2 & 2.7 \\
\hline & 2007 & 20.0 & 20.0 & 51.3 & 2.6 \\
\hline & 2011 & 20.2 & 20.1 & 57.8 & 2.9 \\
\hline & 2015 & 20.2 & 20.1 & 55.6 & 2.8 \\
\hline & 2019 & 20.2 & 20.2 & 52.7 & 2.6 \\
\hline \multirow{5}{*}{$\begin{array}{l}\text { Sierra } \\
\text { Mariscal }\end{array}$} & 2003 & 30.6 & 30.6 & 11.6 & 3.8 \\
\hline & 2007 & 33.7 & 33.7 & 117.6 & 3.5 \\
\hline & 2011 & 34.6 & 32.5 & 111.7 & 3.4 \\
\hline & 2015 & 36.9 & 35.7 & 78.3 & 2.2 \\
\hline & 2019 & 36.6 & 36.4 & 93.0 & 2.6 \\
\hline \multirow{5}{*}{ Soconusco } & 2003 & 75.4 & 74.9 & 232.7 & 3.1 \\
\hline & 2007 & 72.0 & 72.0 & 149.5 & 2.1 \\
\hline & 2011 & 73.3 & 73.0 & 136.9 & 1.9 \\
\hline & 2015 & 73.3 & 67.2 & 70.5 & 1.1 \\
\hline & 2019 & 73.0 & 62.2 & 74.8 & 1.2 \\
\hline \multirow{5}{*}{$\begin{array}{l}\text { Municipio } \\
\text { de } \\
\text { Tapachula }\end{array}$} & 2003 & 26.8 & 26.8 & 89.1 & 3.3 \\
\hline & 2007 & 27.8 & 27.8 & 51.3 & 1.9 \\
\hline & 2011 & 27.8 & 27.8 & 47.5 & 1.7 \\
\hline & 2015 & 27.7 & 27.7 & 25.2 & 0.9 \\
\hline & 2019 & 27.8 & 24.3 & 29.6 & 1.2 \\
\hline
\end{tabular}

Nota: Los datos de superficie y producción se refieren a miles.

Fuente: Servicio de Información Agroalimentaria y Pesquera (SIAP) Secretaría de Agricultura y Desarrollo Rural (SAGARPA) (2020). 


\section{El debate sobre la globalización y las cadenas de producción}

En las últimas décadas se reconoce el alcance del proceso mundializador, pero no la homogeneidad de sus efectos. Ello depende en gran medida del territorio del que se trate, del dinamismo y de los vínculos históricos de sus actores. En el debate sobre el tema de la globalización se pueden identificar tres grandes conjuntos de autores. El primer grupo enfatiza los aspectos económicos y de mercado del proceso de la globalización (grupo "economía y mercado"). El segundo subraya los aspectos políticos de este fenómeno y la relativa independencia de la política sobre la economía (grupo "independencia de la política"). El tercer grupo presta atención a las peculiaridades del proceso de globalización y a las dificultades asociadas con la identificación de patrones universales que lo definen. Para estos últimos autores la globalización es un "terreno de lucha" en el que operan diversas fuerzas socioeconómicas en la búsqueda de sus intereses (grupo "terreno de lucha”). A continuación se analizan las propuestas de cada grupo.

En lo que concierne al grupo "economía y mercado", la referencia fundamental es la idea marxista de la expansión del mercado como condición esencial para el desarrollo del capitalismo (véase, por ejemplo, Dicken, 2015; Robinson, 2014b; Sassen, 1998). En su obra clásica, El Manifesto Comunista (Marx y Engels, 1998 [1848]), se enfatiza que la evolución del capitalismo está vinculada a la capacidad de la burguesía para expandir el tamaño del mercado y con esto la circulación de mercancías y capital (Marx y Engels, 1998 [1848]: 38). La expansión del mercado, continúa, genera el desarrollo de estructuras políticas y dimensiones culturales que consecuentemente facilitan el desarrollo del mercado mismo. En este contexto, se explica la creación no solo del Estado-nación sino también de un sistema económico nacional con una moneda y leyes que lo regulan. Sin embargo, argumenta que la expansión del capitalismo no se detiene en los confines del Estadonación y que los mercados nacionales serán superados, por tamaño y cantidad de lucro, por el mercado global. Este proceso garantiza una mayor circulación y reproducción del capital y, como tal, domina el proceso de reproducción del capitalismo (Marx y Engels, 1998 [1848]: 39-40).

Reflexionando sobre estas observaciones de Marx, los autores del grupo "economía y mercado" ven la evolución de la globalización como una condición estructural del desarrollo del capitalismo. Como tal, los procesos políticos y culturales asociados con la globalización, aun importantes, son considerados secundarios a la expansión del mercado y a la concomitante creación de una clase capitalista global y de una clase trabajadora global (Robinson, 2014b; Sklair, 2001). Los procesos de transnacionalización de la producción y de las finanzas y la creación de circuitos globales de producción y consumo no son ideas arbitrarias de la clase capitalista y de las grandes corporaciones que esta clase controla. Son, más bien, el resultado de la búsqueda de mejores márgenes de ganancias que siempre ha fomentado la expansión del capitalismo.

En este contexto, los autores sostienen que el papel del Estado-nación es el de crear las condiciones para la rápida integración de la economía y de los actores económicos nacionales en circuitos globales de producción y consumo. Simultáneamente, enfatizan los límites de jurisdicción del Estado nacional y la importancia de crear instituciones que puedan apoyar a una economía global. Si bien reconocen que aún no se ha creado un Estado global, hacen hincapié en el surgimiento de instituciones transnacionales como el G-20 (de los 20 países industrializados y emergentes), la Organización Mundial del Comercio (OMC) y el Banco Mundial (BM), que

EntreDiversidades. Revista de Ciencias Sociales y Humanidades, vol. 8, núm. 1 (16), enero-junio 2021. Páginas: 6 - 35 ISSN-e: 2007-7610. https://doi.org/10.31644/ED.V8.N1.2021.A01 
realizan tareas reguladoras vitales a escala mundial. Las contradicciones de la falta de regulación global de la economía permiten que algunos Estados nacionales perturben el funcionamiento del mercado mundial. Esta situación continuará hasta que se establezca una forma más sólida y estable del Estado global. Como en el caso del Estado-nación, agregan, el Estado global está controlado por la emergente clase capitalista global . Esta clase, concluyen, no está vinculada a los intereses de ningún país o región en particular. Pero están preocupados por mantener la estabilidad de la economía global y el libre flujo de bienes, servicios y de trabajadores.

El segundo grupo ("independencia de la política") está compuesto por autores que enfatizan la continua importancia del Estado-nación en el contexto de una economía y sociedad global emergente (ver Arrighi, 2010; Chase-Dunn, 1998; Hardt y Negri, 2001; Harvey, 2003). Empleando el concepto de "imperio", subrayan la continuidad de la fase global del capitalismo actual con sus fases anteriores y enfatizan la importancia de observar las largas tendencias que definen el sistema capitalista. La idea central es que la economía y la sociedad mundiales son un sistema de naciones. En consecuencia, el concepto de economía y sociedad global debe entenderse en términos de un sistema de naciones que, si bien está mucho más integrado que en el pasado, no está a punto de disolverse. Entre estas naciones están los hegemones mundiales y, en el caso del periodo posterior a la Segunda Guerra Mundial, el país más poderoso del mundo ha sido Estados Unidos. Los Estados Unidos fueron originalmente desafiados por la Unión Soviética, pero actualmente China ha asumido el papel de retador, en consecuencia, la economía global actual es un sistema bipolar en el que ahora Estados Unidos y China son los dos líderes mundiales. Según esta comprensión de la economía y la sociedad global, los circuitos mundiales de producción y consumo están mediados por la intervención de las dos superpotencias y sus negociaciones políticas. Así pues, la economía no tiene una evolución libre, sino que es un sistema guiado por los intereses políticos de las superpotencias y sus aliados.

Publicaciones recientes han subrayado el resurgimiento de tendencias proteccionistas fomentadas por enfoques populistas que han ganado popularidad en foros nacionales e internacionales (ver Diamond, 2019; Green, 2019). De acuerdo con esta literatura, la visión proteccionista del populismo conservador minimiza la importancia de los mercados globales y la fuerza de los intereses económicos que están detrás de ellos. Simultáneamente, sobrestiman la capacidad de las medidas políticas nacionales para alterar las condiciones estructurales existentes. En última instancia, ven el proteccionismo como un expediente político de corta duración que no puede alterar los cambios estructurales generados por la evolución global del capitalismo.

El tercer grupo de autores ve la economía y la sociedad globales como "un terreno de lucha" entre grupos sociales opuestos (ver Crouch, 2011; Streeck, 2014, 2016). Estos autores destacan que la globalización no es un fenómeno estructural ni político, sino un proceso histórico basado en las acciones de las clases sociales. Por esta razón, la globalización no puede verse como un proceso lineal que se expande de manera gradual y constante en la sociedad; por el contrario, la evolución de la globalización ha sido siempre cuestionada y resistida por algunos grupos y promovida por otros. En efecto, desde el origen del capitalismo, la ampliación del mercado global siempre ha sido opuesta por fuerzas sociales que vieron en la integración y expansión de los mercados una amenaza para sus intereses económicos y políticos.

EntreDiversidades. Revista de Ciencias Sociales y Humanidades, vol. 8, núm. 1 (16), enero-junio 2021. Páginas: 6 - 35 ISSN-e: 2007-7610. https://doi.org/10.31644/ED.V8.N1.2021.A01 
Desde la última década del siglo XX, la expansión económica, política y cultural de la globalización ha generado reacciones negativas que muchas veces se han asociado a fenómenos y movimientos como el localismo, el tribalismo y un sinfín de episodios violentos, pero también de protesta orientada a la justicia social en contra de las grandes corporaciones. Al mismo tiempo, la globalización ha sido elogiada por ser un proceso que promueve oportunidades para una mayor igualdad social y desarrollo socioeconómico. Los autores de este grupo, también, enfatizan que estos puntos de vista opuestos y los grupos que los apoyan representan los muchos lados de la globalización y su complejidad y la dimensión conflictiva de este fenómeno como resultado de las luchas entre grupos. Si bien es posible argumentar que algunos de estos aspectos han perdido tracción, se puede observar que han surgido otros nuevos como el caso del populismo. Estos autores concluyen que es muy difícil escapar de la globalización, ya que la integración de los mercados y el alcance global de la interacción social son difíciles de limitar. Al mismo tiempo, es prácticamente imposible asumir un desarrollo unilineal de la globalización, debido a que su contestación es uno de los fenómenos más relevantes de la sociedad contemporánea.

En este marco, la agricultura y los alimentos contribuyen de manera significativa en la profundización de las tendencias de la globalización. La producción y el consumo de los productos agroalimentarios se ha convertido en un asunto transnacional, cuestión evidente desde una perspectiva histórica en el caso del café.

La anterior discusión nos lleva entonces a aclarar el concepto de cadenas de producción aplicado en el presente artículo, para lo cual es importante admitir que tiene una variedad de connotaciones, a partir de elaboraciones históricas desde distintas disciplinas. Señalamos para iniciar la propuesta de Hopkins y Wallerstein acerca de las "cadenas de mercancías" para referirse a una "red de procesos de trabajo y producción cuyo resultado final es una mercancía terminada" (citado en Campling y Selwyn, 2018: 420). En un trabajo de Fletes (2015) se presenta un resumen sobre la evolución del concepto, considerando principalmente las referencias a Cadena Global de Mercancías (CGM que subrayó la operación de relaciones mercantiles y de trabajo en un sistema mundial de producción disperso, pero funcionalmente integrado), posteriormente Cadena Global de Valor (CGV) y después la noción de Redes Globales de Producción (RGP). Mientras el concepto de CGV pone atención en el papel de la creación de valor, diferenciación de valor y captura de valor en un proceso coordinado de producción, distribución y entrega minorista (y por lo tanto ayuda a entender el proceso de globalización), el concepto de RGP coloca su énfasis en el contexto institucional y social de las operaciones comerciales interconectadas (Fletes, 2015).

Campling y Selwyn (2018) realizan una síntesis similar al señalar cinco marcos en estudios de mercancías que se han desarrollado para entender los cambios en la economía mundial desde 1970, a saber: cadena de mercancías, CGM, cadena de valor, CGV, y enfoques de RGP. Sobre la última, estos autores subrayan (citando a Henderson, et al., 2002) su rechazo a la metáfora de cadena, como "esencialmente vertical y lineal" y en favor de una perspectiva "relacional, enfocada en la red", que pueda incorporar vínculos horizontales, diagonales y verticales en los sistemas de producción. El marco de RGP también "problematiza la tendencia de los enfoques de CGM y CGV a ver las empresas líderes como teniendo un monopolio de poder empresarial ya que éstas pueden ser retadas por empresas menores" (Campling y Selwyn, 2018: 423). Además, las

EntreDiversidades. Revista de Ciencias Sociales y Humanidades, vol. 8, núm. 1 (16), enero-junio 2021. Páginas: 6 - 35 ISSN-e: 2007-7610. https://doi.org/10.31644/ED.V8.N1.2021.A01 
empresas están “incrustadas territorialmente", en el "sentido de que ellas absorben, y en algunos casos se ven constreñidas por, las actividades económicas y las dinámicas sociales que existen en los lugares donde se localizan" (Henderson et al. 2002: 450 y 452, citado en Campling y Selwyn, 2018: 423). Estos elementos del enfoque de RGP son los que nutren el análisis que se realiza a continuación, y en ese sentido se inscribe en el tercer grupo de autores revisados sobre globalización. En resumen, se pone atención en las redes de producción de café, entre un conjunto de agentes situados en múltiples nodos, en donde, más que una determinación vertical de principios y estándares de producción, distribución y consumo, las “empresas menores” tienen capacidad de incidir en los resultados y en la conformación de estos vínculos y, en ese sentido, del producto terminado. Estas empresas contienden en diferentes nodos, influidas a su vez por un contexto institucional, social e histórico determinado.

\section{Renovación de las articulaciones entre las transnacionales y los empresarios locales en el Soconusco}

A continuación, se analiza las nuevas articulaciones que, en relación con los procesos de globalización de la industria del café, se han generado en las últimas tres décadas entre los grupos de actores transnacionales y aquellos que están vinculados a escalas local y regional, como son los empresarios de la región del Soconusco. El apartado se centra en las estrategias de coordinación implementadas por comercializadores, torrefactores y distribuidores globales; en las formas en que se concretan esos mecanismos en el territorio y en las respuestas de los empresarios cafetaleros locales. Primero se muestra los actores transnacionales presentes en el Soconusco y las formas básicas en las que operan y se vinculan con los actores de la región.

\section{Presencia de empresas transnacionales de café en el Soconusco}

La anulación en 1989 del sistema de precios y cuotas internacionales de exportación que se había establecido bajo el Acuerdo Internacional del Café de 1962 trajo consigo una serie de cambios reflejados en la inestabilidad de precios, nuevos mercados, agentes y mecanismos de regulación. Aunque algunas compañías importadoras, tostadoras y distribuidoras tienen una larga trayectoria, su operación se vio fortalecida por este proceso y por la restructuración económica y política neoliberal (Venegas, et al., 2020: 16 y 18; Hernández, 2019: 432). En el Soconusco, se puede constatar la presencia, desde la década de los noventa, de por lo menos dos de las cinco grandes empresas transnacionales (ETN) que concentran la mayor parte del comercio: Neumann Kaffee Gruppe (NKG) y ECOM Agroindustrial Corporation Ltd., y una de las principales compañías dedicadas a la distribución de café en el mundo: Nestlé Group ${ }^{3}$.

La primera está representada por Exportadora de Cafés California, S. A. de C. V. (ECC), apoyada en sus operaciones por otra empresa local: Comercializadora e Industrializadora de Productos Chiapanecos, S.A. de C.V. (CIPC). Cabe señalar que la filial (ECC) inició operaciones

${ }^{3}$ Además de las que están presentes en el Soconusco, en este grupo se encuentra también Volcafé (ahora parte de ED \& F Man), la cual tiene como subsidiaria en México a Becafisa; Louis Dreyfus Company (LDC) y Olam International.

EntreDiversidades. Revista de Ciencias Sociales y Humanidades, vol. 8, núm. 1 (16), enero-junio 2021. Páginas: 6 - 35 ISSN-e: 2007-7610. https://doi.org/10.31644/ED.V8.N1.2021.A01 
en la región en 1941, pero se unió a la transnacional en 1993 y juntas logran actualmente una participación en el mercado mexicano de exportación del $20 \%$, lo que posiciona a NKG como una de las principales empresas exportadoras de café del país.

La segunda, ECOM Agroindustrial Corporation Ltd., cuya filial en la región es Agroindustrias Unidas de México, S. A. de C. V. (AMSA), cuenta con la mayor participación en la comercialización del café mexicano; sostiene con la empresa Cafés de Especialidad de Chiapas SAPI de C. V. (Cafesca) una sociedad tipo joint venture. Tiene presencia en México desde 1948, y situó su primera sucursal en Tapachula bajo el nombre de Omnicafé en 1979.

La tercera, Nestlé Group, opera en la región mediante alianzas con alrededor de seis empresas locales, entre las que destaca Exportadora de Granos y Oleaginosas del Sureste, S. A. de C. V, de acuerdo con observaciones de campo se especializa en gestionar la cadena de abasto para la producción de cafés instantáneos, por lo que en su gran mayoría le interesa la variedad robusta, aunque recientemente se ha abastecido de productores de arábiga para algunos productos con la finalidad de atender el segmento de cafés especiales.

Además de estas ETN, hay en la región otras empresas (comercializadoras y torrefactoras) que se abastecen de café soconusquense. Entre ellas, se encuentra Rogers Family Corporation, un tostador norteamericano que comenzó a trabajar desde mediados de los ochenta y que comercialmente se está expandiendo. Específicamente atiende el mercado de los cafés especiales y se provee de café de varias regiones del mundo como Centroamérica, África e Indonesia. Actualmente tiene un par de empresas que operan en la región: Beneficio Bajareque Norte, S. A. de C. V. y Fincas Familia Rogers, S.A. de C.V.

\section{Mecanismos de coordinación emergentes}

Los mecanismos de coordinación que las ETN participantes en el Soconusco han desarrollado recientemente apuntan a garantizar el abasto de acuerdo con sus estándares, mediante el acompañamiento a los productores en sus actividades agrícolas, el financiamiento de proyectos sociales o acciones de "Responsabilidad Social" (RS), la formalización de alianzas estratégicas o el control de propiedades (Ver Tabla 2). 
Tabla 2. Mecanismos de coordinación emergentes de las ETN participantes en el Soconusco

\begin{tabular}{|c|c|c|c|c|}
\hline $\begin{array}{l}\text { Empresa } \\
\text { Transnacional }\end{array}$ & $\begin{array}{l}\text { Acompañamiento a los } \\
\text { productores }\end{array}$ & $\begin{array}{l}\text { Proyectos sociales y } \\
\text { actividades de } R S\end{array}$ & Alianzas & $\begin{array}{l}\text { Control sobre } \\
\text { propiedades }\end{array}$ \\
\hline Nestlé Group & $\begin{array}{l}\text { Aplicación del Código } \\
\text { Común para la } \\
\text { Comunidad Cafetalera y } \\
\text { Plan Nescafé }\end{array}$ & $\begin{array}{l}\text { No lo aplica. Se } \\
\text { enfoca a pequeños } \\
\text { productores }\end{array}$ & No establece & No establece \\
\hline $\begin{array}{l}\text { Neumann } \\
\text { Kaffee Gruppe } \\
\text { (NKG) }\end{array}$ & $\begin{array}{l}\text { A sus aliados, coaching } \\
\text { e información } \\
\text { de mercados; a } \\
\text { sus proveedores, } \\
\text { acompañamiento } \\
\text { en diferentes sellos, } \\
\text { estándares, programas y } \\
\text { certificaciones }\end{array}$ & $\begin{array}{l}\text { Se desarrollan } \\
\text { mediante la Fundación } \\
\text { Hanns R. Neumann } \\
\text { Stiftung (HRNS) con } \\
\text { varias líneas de acción }\end{array}$ & $\begin{array}{l}\text { Mediante } \\
\text { las empresas } \\
\text { Exportadora de } \\
\text { Cafés California y } \\
\text { Comercializadora } \\
\text { e Industrializadora } \\
\text { de Productos } \\
\text { Chiapanecos, S.A. } \\
\text { de C.V. (CIPC) }\end{array}$ & $\begin{array}{l}\text { Mediante socios } \\
\text { locales, dueños } \\
\text { de las fincas }\end{array}$ \\
\hline $\begin{array}{l}\text { Ecom } \\
\text { Agroindustrial } \\
\text { Corporation } \\
\text { Ltd. }\end{array}$ & $\begin{array}{l}\text { Incorporación de los } \\
\text { compradores a su cadena } \\
\text { de suministro Programa } \\
\text { de "formación de } \\
\text { proveedores" }\end{array}$ & No establece & No establece & $\begin{array}{l}\text { Adquisición de } \\
\text { propiedades }\end{array}$ \\
\hline $\begin{array}{l}\text { Rogers Family } \\
\text { Company Inc. }\end{array}$ & $\begin{array}{l}\text { Asesoramiento directo } \\
\text { en la finca basado en } \\
\text { experiencia adquirida en } \\
\text { otras parcelas, ya sean } \\
\text { de su propiedad o de sus } \\
\text { proveedores o socios }\end{array}$ & $\begin{array}{l}\text { Son incorporados a } \\
\text { las negociaciones y se } \\
\text { desarrollan mediante } \\
\text { su fundación. } \\
\text { También, se pagan } \\
\text { primas de precios por } \\
\text { arriba del costo de } \\
\text { producción (similar al } \\
\text { esquema de Comercio } \\
\text { Justo) }\end{array}$ & Con varias fincas & $\begin{array}{l}\text { Sociedad y } \\
\text { adquisición }\end{array}$ \\
\hline
\end{tabular}

Fuente: Elaboración propia con base en trabajo de campo.

\section{a) Acompańamiento a los productores}

Según sus documentos corporativos, Nestlé busca promover las mejores prácticas corporativas sustentables e impulsar la productividad y tecnología del café para asegurar la sustentabilidad de la producción y el consumo del café. En el año 2010, implementó un plan —denominado "Nescafé"para lograr que los cafeticultores cumplieran con el Código Común para la Comunidad Cafetalera (4C), desarrollado en el año 2003 por la DKV (Deutscher Kaffeeverband, Asociación Alemana del Café) y la GTZ (Gesellschaft für Technische Zusammenarbeit, Sociedad para la Cooperación

EntreDiversidades. Revista de Ciencias Sociales y Humanidades, vol. 8, núm. 1 (16), enero-junio 2021. Páginas: 6 - 35 ISSN-e: 2007-7610. https://doi.org/10.31644/ED.V8.N1.2021.A01 
Técnica). Con ello, promueven la implementación de estándares de producción, procesamiento y consumo del café sustentables evitando diez prácticas inaceptables y 28 principios de mejora (Nestlé Group, 2004, 2011a, 2011b). En el marco del mismo plan "Nescafé", proponen el empleo de tecnología genética con el objeto de mejorar la resistencia y los rendimientos de las plantaciones de café y proveer de cafetos a los cafeticultores proveedores (Alonso, 2011).

Neumann Kaffee Gruppe (NKG) tiene un equipo de agrónomos que viaja continuamente por las diferentes regiones productoras de café en México para promocionar y mejorar el cultivo de café bajo estándares y principios sostenibles. Estos son certificados por organizaciones independientes, entre las cuales se encuentra el sello Rainforest Alliance, los estándares UTZ y Organic Crop Improvement Association (OCIA), el Código Común para la Comunidad Cafetalera, el programa Coffee and Farmer Equity (C.A.F.E.), el sistema Fairtrade o Comercio Justo y las certificaciones IMO Control, Naturland y Silliker (NKG, 2020).

La propuesta de ECOM Agroindustrial Corp. se sustenta en el establecimiento de una cadena de suministro integrada a la empresa para dotar de asistencia técnica a los productores; promover comunidades resilientes con repercusiones en los ámbitos social y económico; incrementar la productividad de las plantaciones y generar una inclusión financiera en los agricultores (ECOM, 2020). Su programa de desarrollo de proveedores consiste en facilitar y proveer servicios integrales en los siguientes rubros: rediseño de la cadena de valor; asistencia técnica; transferencia tecnológica; investigación y desarrollo; financiamiento; inversiones sociales, e intercambio de experiencias. Teddy Esteve, socio mayoritario de la empresa, afirma:

Antes de 1997, realmente no teníamos muchas relaciones directas con los productores. Compramos a través de intermediarios. Las primeras experiencias con la rastreabilidad y la certificación nos mostraron el camino hacia una relación directa con los agricultores. Los agricultores no solo mejoraron sus ingresos a partir de la certificación y con el tiempo a partir de una mejor calidad y rendimiento, sino que evitaron a los intermediarios que anteriormente se habían llevado una gran parte del pastel (citado en Rosenberg, Eckstein y Brett, 2009: 13).

Por su parte, la compañía Rogers promueve prácticas para mejorar la calidad y cantidad de lo que producen los cafeticultores en sus plantaciones que abarcan desde el cultivo hasta la venta del café, prácticas que la misma empresa ha desarrollado en fincas de su propiedad en Kona (Hawaii, Estados Unidos), Panamá, Ruanda y México (San Francisco Bay Coffee, 2020). Sobre este caso, un empresario local afirma:

Pete [Rogers] siempre fue un cliente atípico porque en primer lugar es el dueño de la empresa el que llega y te visita cada ańo. Llega y se mete a las galleras [dormitorios] de los trabajadores, a ver cómo vive la gente. Entonces, no es un comprador tradicional que dice "mándame una muestra”. Él se mete hasta la cocina, pues. Se mete en tu beneficio y te desarma la máquina; revisa que tan limpia está. Te pregunta “¿En dónde está pasando mi café?”. Para eso debes tener un beneficio pulcro y azulejos en todos lados. Las galleras deben estar bien y si no lo están, él te ayuda (Entrevista a Bracamontes, 2011, propietario de la Finca Perú-París).

EntreDiversidades. Revista de Ciencias Sociales y Humanidades, vol. 8, núm. 1 (16), enero-junio 2021. Páginas: 6 - 35 ISSN-e: 2007-7610. https://doi.org/10.31644/ED.V8.N1.2021.A01 


\section{b) Proyectos sociales y Responsabilidad Social}

Además de las relaciones directas con productores, otro tema novedoso en cuanto a los mecanismos de coordinación de las ETN es el desarrollo de proyectos sociales y acciones de Responsabilidad Social (RS). Por un lado, las fincas han sido criticadas históricamente por las condiciones de vida de sus trabajadores, principalmente de los eventuales. Por otro, a pesar de que la normatividad mexicana establece programas para protección de los trabajadores, en los países consumidores persiste la legítima preocupación por el trato que se da a ese sector laboral. Es así como las ETN plantean mecanismos dirigidos a mejorar las condiciones de vida de los trabajadores y de las comunidades en donde se ubican las plantaciones. En el caso de Rogers, incorpora los proyectos sociales como parte de sus acuerdos:

Don Pete Rogers siempre ha estado motivando el desarrollo social, desde hace 15 o 20 años que él está en esto. Él, cuando empieza una relación con una finca, motiva que esa finca haga inversiones en el tema de mejorar las condiciones de vida de los trabajadores y él contribuye en esa inversión como un donativo a los proveedores de café (Entrevista a Bracamontes, 2011, propietario de la Finca Perú-París).

A la fecha, esta empresa manifiesta haber construido más de mil setecientas viviendas, 63 escuelas y una docena de clínicas para los jornaleros a través de la Rogers Family Foundation (SF Bay Coffee, 2020). En el año 2010, se reportó la existencia de 36 proyectos de ayuda en México, Centroamérica, África e Indonesia. De esos proyectos, catorce se desarrollaron en plantaciones de la región del Soconusco.

Por otro lado, NKG estableció la Fundación Hanns R. Neumann Stiftung, con cuatro líneas de acción: 1) promover una economía de café sostenible mediante proyectos de desarrollo basados en la iniciativa "Asociación para la sostenibilidad"4; 2) ayudar a conservar los recursos naturales con educación técnica sobre prácticas de una agricultura sostenible; 3) apoyar la protección del medio ambiente con proyectos educativos y de conservación para jóvenes; y 4) buscar mejores condiciones sociales en los países productores a través de proyectos en cooperación con organizaciones nacionales e internacionales. Sostiene que el acompañamiento que brinda "a los agricultores va más allá de la productividad y la calidad del café” y que busca apoyarlos para que, junto con sus familias, aumenten sus ingresos y su posición competitiva, además de "liberar el potencial de las generaciones jóvenes para dar forma a las áreas rurales del futuro" (Hanns R. Neumann Stiftung, 2019).

\section{c) Control de propiedades}

De las cuatro ETN mencionadas en la Tabla 2, únicamente Nestlé Group no busca tener control operativo, alianzas o se ha hecho propietaria de alguna finca. Las otras tres han implementado estrategias en ese sentido.

\footnotetext{
${ }^{4}$ Esta iniciativa fue creada por la International Coffee Partners (2019), en donde participan Lavazza (de Italia), Löfbergs (Suecia), Paulig (Finlandia) y Tchibo (Alemania).
}

EntreDiversidades. Revista de Ciencias Sociales y Humanidades, vol. 8, núm. 1 (16), enero-junio 2021. Páginas: 6 - 35 ISSN-e: 2007-7610. https://doi.org/10.31644/ED.V8.N1.2021.A01 
Neumann Kaffee Gruppe (NKG), mediante su alianza con Exportadora de Cafés California, supervisa la operación de al menos siete fincas en el Soconusco - Génova, Maravillas, España, Alianza, Independencia, Triángulo y Campamento-, algunas de ellas administradas por la empresa Comercializadora e Industrializadora de Productos Chiapanecos, S.A. de C.V. (NKG, 2020; CIP, s/f). La mayoría de las plantaciones son propiedad de la familia Luttmann, quien, en el marco de la alianza con NKG, está condicionada a entregar su producción a la transnacional que se encarga de colocarla en "mejores condiciones" en comparación a lo que podría hacer el empresario por su cuenta.

ECOM Agroindustrial Corporation Ltd se vincula con propiedades a través de su subsidiaria Agroindustrias Unidas de México (AMSA), propietaria de 20 fincas en Chiapas. Una de ellas, La Gloria Zaju, es de las pocas fincas del Soconusco a más de $1200 \mathrm{msnm}$-altitud indicada en algunos estándares internacionales como café de estricta altura- También tiene propiedades en Villa Comaltitlán y Motozintla, este último en la región Sierra (Mercanta, 2016).

La compañía Rogers ha adquirido varias plantaciones en el Soconusco desde 1999, entre las que se encuentran Rancho Cuilco, de 150 hectáreas, Rancho La Paz, de 161.8 ha, y Finca Perú Paris, de 202.3 ha, y la tendencia apunta a que compre más propiedades ${ }^{5}$, de acuerdo con información recogida en campo. Para la compañía Rogers, adquirir propiedades tiene que ver en primera instancia con una estrategia de abastecimiento de café orgánico en fincas bajo su control y además el envío de diferentes mensajes a los otros actores de la cadena: 1) hacia los distribuidores: ser una empresa que cubre toda la cadena y garantiza el abasto porque "cultiva, importa y tuesta su propio café", pues posee fincas en donde controlan la calidad de la producción y abasto de café verde y 2) hacia los distribuidores y consumidores finales: ser una empresa con poca o nula huella de carbono por implementar mejoras y buenas prácticas en la torrefacción y otras actividades en la producción de café en todas sus instalaciones, incluidas las fincas que posee.

Asimismo, contar con fincas en la región de abastecimiento permite a esta empresa conocer los costos de producción locales, pues varían mínimamente respecto a los reportados en las fincas en donde compra café. Además, con un control eficiente de la producción en las fincas de su propiedad puede reducir los costos de su insumo, el café verde, e implementar mejoras e innovaciones en el proceso productivo que después compartirá con sus proveedores.

\section{Las respuestas. Diversificación, calidad en el producto y revaloración de atributos intangibles}

Como se dijo antes, la participación histórica de los empresarios locales en la industria del café les ha dotado de relaciones comerciales, así como de un bagaje sociocultural importante para manejar los cambios económicos y sociales de diferentes escalas. Frente a las estrategias de las ETN existen mecanismos creativos para salir adelante, situación que se puede ver en al menos tres casos.

En primer lugar, se puede mencionar el caso de la Finca San Francisco, cuya diversificación de actividades económicas le permite la oportunidad de trabajar en la floricultura y en el cultivo de palma de aceite en las temporadas de bajos precios del café; mientras que toma ventaja del

${ }_{5}^{5}$ Esta ETN crea la empresa Fincas Familia Rogers, S.A. de C.V. para administrar sus propiedades en Chiapas.

EntreDiversidades. Revista de Ciencias Sociales y Humanidades, vol. 8, núm. 1 (16), enero-junio 2021. Páginas: 6 - 35 ISSN-e: 2007-7610. https://doi.org/10.31644/ED.V8.N1.2021.A01 
negocio de la cafeticultura en las etapas de precios altos, pues su finca — que se encuentra ubicada a una altitud mayor a $1200 \mathrm{msnm}$ - obtiene un café de estricta altura. Se agrega también los servicios de hospedaje y alimentación que ofrece a través de un hotel boutique.

Otro productor, propietario de Finca Hamburgo (FH), tuvo una experiencia de negociación favorable con la transnacional Starbucks Coffee Company. Antes de esto, FH había logrado un vínculo con la torrefactora estadounidense Seattle's Best Coffee (SBC), debido a que otra finca de la región, anterior proveedora de esta torrefactora, cambió de dueño y el nuevo propietario canceló el trato por la responsabilidad que implicaba. Entonces, FH y SBC hicieron contrato con precios justos — con un análisis previo de calidad que exigió la empresa norteamericana, así como un reconocimiento por parte de esta de la garantía de abasto que $\mathrm{FH}$ ofrecía-. Unos años después, Starbucks compró Seattle Best Coffee y, automáticamente, FH se volvió proveedora directa de Starbucks, condición que se volvió a poner a prueba cuando Starbucks contrató a AMSA como una empresa coordinadora de proveedores en México. El propietario de FH afirma:

[En 2009, Starbucks] hizo un contrato con AMSA para que ellos fueran sus representantes en México y por petición mía yo sigo haciendo tratos con [Starbucks]. [Hablé] con los directores en Suiza y les dije que yo no quería ese triángulo, ya que yo era responsable de mi calidad y que no iba a dejar que nadie más tocara mi café, y lo aceptaron y de eso no tiene la oportunidad mucha gente (Entrevista a Edelmann, 2011).

Un tercer caso corresponde a la Finca Irlanda, de Bern Peters, que después de diez años de hacer negocios con el torrefactor estadounidense Rogers — de 2000 a 2010_, resolvió concluir esa larga relación y establecer una Sociedad con uno alemán (Lebensbaum), con quien trabaja en un esquema de proyectos sociales parecido al de su cliente norteamericano. Su principal argumento para romper la relación anterior fue que su producto poseía, y posee, una característica poco comprendida y posicionada en el gusto del consumidor. En su negociación con el estadounidense, planteó la necesidad de reconocimiento en precio por el sello biodinámico que usaba la finca, asociado con el tipo de agricultura que desarrolla desde $1967^{6}$, así como el registro del origen en la etiqueta del producto final. Este empresario tiene, por otro lado, un cliente torrefactor suizo (Henauer) que vende desde hace muchos años su café en una bolsa con el nombre de la finca y una imagen de un pequeño tren. Por todo ello, exigió un precio mayor al que antes recibía y, ante la negativa, resolvió establecer la sociedad con su cliente alemán que sigue vigente a la fecha.

El resumen de las estrategias de las fincas del Soconusco frente a los cambios en la regulación de la industria del café y la presencia de las transnacionales se muestra en la Tabla 3.

\footnotetext{
${ }^{6}$ La agricultura biodinámica se basa en la teoría de Rudolf Steiner, filósofo austriaco que definió un modelo ideal de una granja agrícola como un sistema biológico-dinámico en armonía con la naturaleza y el cosmos, que al considerarlo un ecosistema único, basado en sus aspectos ecológicos, económicos y sociales, se transforme en autosuficiente con respecto al ciclo de sustancias que requiere, reciclándolas, manteniendo e incrementando la fertilidad del suelo mediante el uso de compostas producidas en la misma granja. También se emplean preparados biodinámicos, que tienen la función de regular e influir en el proceso de degradación de la composta, estimulando la vida en suelo de miles de microorganismos y activando la fotosíntesis de las plantas (Ecoagricultor, s/f).
}

EntreDiversidades. Revista de Ciencias Sociales y Humanidades, vol. 8, núm. 1 (16), enero-junio 2021. Páginas: 6 - 35 ISSN-e: 2007-7610. https://doi.org/10.31644/ED.V8.N1.2021.A01 
Tabla 3. Estrategias en la diversificación de actividades económicas en las fincas del Soconusco

\begin{tabular}{|c|c|c|c|c|c|c|}
\hline Finca & Café & Servicios turísticos & Flores & $\begin{array}{l}\text { Café tostado y } \\
\text { molido }\end{array}$ & $\begin{array}{l}\text { Cafetería (fuera } \\
\text { de la finca) }\end{array}$ & Otras \\
\hline Argovia & $\begin{array}{l}\text { Ambos sistemas: } \\
\text { convencional } \\
\text { y orgánico; } \\
\text { calidad prima } \\
\text { lavado; mercado } \\
\text { estadounidense }\end{array}$ & $\begin{array}{l}\text { Hotel Argovia Finca } \\
\text { Resort }\end{array}$ & $\begin{array}{l}\text { Argovia Rio Cuilco } \\
\text { Flores y Follajes } \\
\text { Tropicales (flores } \\
\text { tropicales) }\end{array}$ & $\begin{array}{l}\text { Distribución local } \\
\text { por Diversificados } \\
\text { Argovia }\end{array}$ & & \\
\hline Hamburgo & $\begin{array}{l}\text { Convencional; } \\
\text { calidad estricta } \\
\text { altura; mercado } \\
\text { estadounidense y } \\
\text { europeo }\end{array}$ & $\begin{array}{l}\text { Hotel Finca } \\
\text { Hamburgo }\end{array}$ & & $\begin{array}{l}\text { Ventas por } \\
\text { Internet }\end{array}$ & $\begin{array}{l}\text { Dos en Ciudad } \\
\text { de México. }\end{array}$ & \\
\hline Irlanda & $\begin{array}{l}\text { Orgánico- } \\
\text { biodinámico; calidad } \\
\text { estricta altura; } \\
\text { mercado europeo y } \\
\text { estadounidense }\end{array}$ & $\begin{array}{l}\text { Estuvo inscrita } \\
\text { en Proyecto Ruta } \\
\text { del Café, pero } \\
\text { actualmente no ofrece } \\
\text { estos servicios }\end{array}$ & & $\begin{array}{l}\text { Distribuido } \\
\text { por Productos } \\
\text { Naturales de la } \\
\text { Región Maya, } \\
\text { S.A. de C.V. } \\
\text { (productos de la } \\
\text { finca envasados) }\end{array}$ & $\begin{array}{l}\text { Franquicia de } \\
\text { sus cafeterías; } \\
\text { Actividad } \\
\text { económica } \\
\text { relacionada con } \\
\text { la cadena de } \\
\text { valor del café }\end{array}$ & \\
\hline Rancho Alegre & $\begin{array}{l}\text { Orgánico; café de } \\
\text { especialidad; mercado } \\
\text { nacional }\end{array}$ & $\begin{array}{l}\text { Estuvo inscrita } \\
\text { en Proyecto Ruta } \\
\text { del Café, pero } \\
\text { actualmente no ofrece } \\
\text { estos servicios }\end{array}$ & & $\begin{array}{l}\text { Distribución local, } \\
\text { las cadenas de } \\
\text { supermercados } \\
\text { les piden } 60 \\
\text { días de crédito } \\
\text { o mercancía a } \\
\text { consumo }\end{array}$ & $\begin{array}{l}\text { Cafeterías en } \\
\text { Tapachula, } \\
\text { Querétaro y } \\
\text { Cuernavaca }\end{array}$ & \\
\hline $\begin{array}{l}\text { Helda y San } \\
\text { Francisco }\end{array}$ & $\begin{array}{l}\text { Convencional; café } \\
\text { de especialidad } \\
\text { (probablemente prima } \\
\text { lavado); mercado } \\
\text { estadounidense }\end{array}$ & $\begin{array}{l}\text { Sí, pero no es su } \\
\text { principal actividad }\end{array}$ & $\begin{array}{l}\text { Mediante la } \\
\text { empresa Chiapas } \\
\text { Flower: orquídeas } \\
\text { y anturios. La } \\
\text { ventaja competitiva } \\
\text { que tienen en esta } \\
\text { actividad es que } \\
\text { abarcan casi toda } \\
\text { la cadena de valor: } \\
\text { producen, transportan } \\
\text { y distribuyen. } \\
\text { Únicamente les } \\
\text { hace falta tener } \\
\text { florerías para llegar } \\
\text { directamente al } \\
\text { consumidor final }\end{array}$ & & & $\begin{array}{l}\text { Cultivo } \\
\text { de palma } \\
\text { africana }\end{array}$ \\
\hline Perú-Paris & $\begin{array}{l}\text { Orgánico; café } \\
\text { de especialidad } \\
\text { (probablemente prima } \\
\text { lavado); mercado } \\
\text { estadounidense }\end{array}$ & $\begin{array}{l}\text { Estuvo inscrita } \\
\text { en Proyecto Ruta } \\
\text { del Café, pero } \\
\text { actualmente no ofrece } \\
\text { estos servicios }\end{array}$ & & & & \\
\hline Chapultepec & $\begin{array}{l}\text { Ambos sistemas: } \\
\text { convencional y } \\
\text { orgánico, según } \\
\text { disponibilidad de } \\
\text { recursos; calidad } \\
\text { prima lavado; vende a } \\
\text { empresa transnacional } \\
\text { que acapara café }\end{array}$ & & & & & $\begin{array}{l}\text { Venta de } \\
\text { fracciones } \\
\text { de terreno } \\
\text { de la finca }\end{array}$ \\
\hline
\end{tabular}

Fuente: Elaboración propia con base en trabajo de campo.

EntreDiversidades. Revista de Ciencias Sociales y Humanidades, vol. 8, núm. 1 (16), enero-junio 2021. Páginas: 6 - 35 ISSN-e: 2007-7610. https://doi.org/10.31644/ED.V8.N1.2021.A01 


\section{Efectos en el territorio}

La tendencia global identificada en la década de 1990 — de una mayor atención del consumidor en el origen de los alimentos, inocuidad, calidad y las condiciones sociales de producción de los alimentos - conllevó, además de espacios como el de RS, el de la certificación orgánica de los productos alimentarios (Marsden, et al., 2010). Este último proceso fue desarrollado por organizaciones sociales de diversas regiones de Chiapas (Hernández, 2019: 434). Representa uno de los impactos más claros de la reestructuración de la industria del café en el Soconusco. Se identificó en los actores empresariales un cambio de concepción respecto al requerimiento de un sello orgánico que les permitiría entrar a un mercado con diversos gustos, intereses y niveles de ingresos, variables que forman parte de los términos con que operan e imponen los actores que coordinan la industria. Sin embargo, desde la perspectiva de los empresarios cafetaleros del Soconusco, este espacio les permitió valorar y dominar otras opciones comerciales como fue el mercado de cafés especiales.

Las ETN son las intermediarias entre la producción y el consumo. Conocen bien la diversidad de preferencias y los requisitos de cada segmento de mercado. En su búsqueda por atender dichos requisitos, en algún momento los empresarios de la región consideraron que las certificaciones eran estrictamente necesarias para la comercialización de su producción en ciertos mercados, pero justo la relación comercial de más de una década con el tostador estadounidense mencionado les cambió la perspectiva y decidieron mantener las prácticas de producción orgánica, más no el certificado. De hecho, la exigencia se transformó en algo más difícil de alcanzar, pero al mismo tiempo más tangible: la conservación de la diversidad ecológica en las fincas. Para esto, Rogers (como parte de las alianzas que se han establecido) paga a una empresa especializada, la Cooper Ecological Monitoring, Inc., por la realización de evaluaciones en el conjunto de plantaciones de donde se abastece de café (ver Cooper, 2006 y 2016).

En ese sentido, hay fincas cuya producción no es "colocada" en el mercado orgánico, pero sí en el de cafés de especialidad y, por lo tanto, no requieren el certificado, así que algunas ETN dejan de exigirlo, pero para mantener un estatus de empresas responsables con el cuidado al medio ambiente promueven prácticas amigables y financian acciones para su evaluación. Henderson (2019: 408) expone que "para los productores del café orgánico, la certificación se ha convertido progresivamente en un requisito mínimo para poder entrar a los nichos de exportación en los últimos ańos. Aunque ofrece un precio encima del convencional, hoy en día el factor preponderante que influye en los precios y en la posibilidad de entrar en el mercado orgánico y gozar de su bono de precio es la calidad del grano, no la certificación en sí”.

El otro efecto en el territorio es el cambio en el patrón productivo en zonas bajas de la región como respuesta a los mecanismos de control existentes en las cadenas globales, a los vaivenes de los precios del mercado internacional del café y al cambio climático. El peor escenario para la región cafetalera del Soconusco sería que se profundice la caída en la superficie sembrada como resultado de estos factores (Tabla 1). En estas zonas, la primera opción de cambio ha sido sustituir las plantas de café arábiga por robusta, cuya producción se puede entregar a cualquier empresa que forme parte de la cadena de suministro de Nestlé, con fuerte presencia en la región.

${ }^{7}$ Esta ETN compra café "robusta" para elaborar, entre otros productos, el instantáneo Nescafé. Gran parte de esa

EntreDiversidades. Revista de Ciencias Sociales y Humanidades, vol. 8, núm. 1 (16), enero-junio 2021. Páginas: 6 - 35 ISSN-e: 2007-7610. https://doi.org/10.31644/ED.V8.N1.2021.A01 


\section{Flexibilidad de las estrategias de los empresarios locales}

Es necesario analizar más a fondo la concurrencia de distintos recursos (materiales e inmateriales), conocimientos y relaciones en las estrategias que los empresarios de la región han establecido frente a las dinámicas de las cadenas de producción de café. A continuación, se presentan dos casos sobre esta experiencia de tales actores con información obtenida en campo.

\section{Finca Argovia}

Argovia ha logrado una diversificación económica y se mantiene en el negocio del café, a pesar de que la altura de la finca no es la recomendada, pero logra competir en el mercado de cafés especiales, mientras que otras con esa misma altura han sucumbido o han establecido plantaciones de café robusta, en el mejor de los casos. La finca ha incorporado actividades como el turismo y la producción de flores tropicales, sin dejar de producir café, de acuerdo con las reglas que impone el mercado para el nicho de café de especialidades.

Cuando la finca inició un sistema de agricultura orgánica, la producción bajó de veinte mil a quince mil quintales por ciclo. En parte, había disminuido la aplicación de agroquímicos y fertilizantes porque el precio del café era inferior a los costos de producción; aplicaba algunos herbicidas ya que los cafetales lo requerían como uno de los productos básicos para su crecimiento. Entre 2006 y 2007, la empresa obtuvo su primera certificación estadounidense de Rainforest Alliance, así como el sello Bird Friendly del Smithsonian's National Zoo \& Conservation Biology Institute. Además, solicitó los servicios de la certificadora IMO Control para vender en los mercados de Europa. Estas certificaciones, impuestas como requisito de los clientes para comprar el aromático, corresponden a los nichos de mercado que atienden; es decir, no son decisión independiente de la empresa, sino una demanda del comprador. Cada mercado tiene exigencias plasmadas en las normas correspondientes y Argovia las atiende para estar en posibilidades de comercializar su café en dichos mercados.

El propietario de la finca, Bruno Giesemann, ha reconocido que, por la disminución de los precios internacionales del café, el futuro de la propiedad incursionó en la diversificación de sus actividades. Siguiendo esta directriz, impulsa una estrategia empresarial que consiste en la transformación del tradicional casco de una histórica finca en una moderna infraestructura para el alojamiento de turistas (Hotel Argovia Finca Resort), así como en la creación y desarrollo de la empresa dedicada a la agroindustria, Diversificados Argovia, S. A. de C. V., y de Argovia Rio Cuilco Flores y de Follajes Tropicales.

Argovia se encuentra entre las trece fincas que la Secretaría de Turismo de Chiapas incluyó en La Ruta del Café, en el marco de un proyecto para convertirlas en prestadoras de servicios turísticos con el acompańamiento y la orientación de algunas dependencias de gobierno estatal. Anteriormente, visitaban esta y otras fincas familiares y amigos de los dueños, así como clientes,

producción es consumida en el país. Esta compañía alienta la conversión de plantaciones de arábica a robusta para garantizar su abasto mediante la alianza con Exportadora de Granos y Oleaginosas del Sureste, S. A. de C. V., retirada de otras regiones productoras de México, menos de Chiapas, donde tiene dos beneficios, uno en Tapachula y otro en Ángel Albino Corzo. Además de esa empresa, sirven de intermediarios a Nestlé otras seis compañías en el Soconusco, las cuales por lo regular compran café cereza y venden a Nestlé café oro para agregar valor y obtener mejor renta.

EntreDiversidades. Revista de Ciencias Sociales y Humanidades, vol. 8, núm. 1 (16), enero-junio 2021. Páginas: 6 - 35 ISSN-e: 2007-7610. https://doi.org/10.31644/ED.V8.N1.2021.A01 
académicos o invitados interesados en conocer por distintos motivos el proceso de producción de café. Algunas de ellas, de hecho, han sido objeto de investigación de universidades e instituciones mexicanas y del extranjero; pero no habían abierto sus puertas al turismo, a pesar de la belleza del paisaje y su historia.

Argovia tiene más demanda de estos servicios que otras fincas similares debido a que es la más cercana a Tapachula, la más accesible por carretera y mantiene una reconocida calidad en sus instalaciones para hospedaje y alimentación. Cuenta con los sellos de calidad distintivos $\mathrm{H}, \mathrm{M} \mathrm{y}$ Tesoros de México ${ }^{8}$. Estos reconocimientos han permitido ganar un lugar privilegiado respecto a otras fincas de la región, como Hamburgo, Irlanda y San Francisco.

La finca se ha vinculado con la Asociación Mexicana de Turismo de Aventura y Ecoturismo (AMTAVE), constituida en 1994 y en el ámbito local con agencias de viajes como Crucero Tours de Tapachula. Además, promueve sus servicios en periódicos y revistas de circulación nacional, tiene campańas televisivas y eventos en que se da a conocer La Ruta del Café.

Esta empresa ha incursionado exitosamente, como antes se mencionó, en el cultivo de plantas ornamentales, flores y follajes tropicales, entre las cuales se encuentran anturios, heliconias, hawaianas, maracas, aves de paraíso, drácenas, palmas y otras especies. Se producen en 34 hectáreas con el certificado Rainforest Alliance. Por medio de los Fideicomisos Instituidos en Relación con la Agricultura (FIRA) ${ }^{9}$ se obtuvo financiamiento para capacitar al personal encargado de las plantas ornamentales mediante cursos impartidos por técnicos costarricenses. Los requerimientos de los compradores se asocian con la variedad, el color, la textura y el tamaño de las flores. Para atender estos requerimientos, la empresa cuenta con registros de los requisitos de cada cliente en hojas de cálculo, porque más que un estándar como en el café, en la comercialización de plantas ornamentales los criterios son muy variados y dependen del gusto de cada cliente. No hay contratos establecidos con las florerías, sino pedidos, por lo que la demanda fluctúa, según el nicho de mercado.

En resumen, la estrategia que ha seguido esta empresa ha sido la diversificación de sus actividades incursionando en la producción y comercialización de flores y los servicios turísticos, al tiempo que cuida la calidad de su café para competir en el mercado de los cafés especiales. Así, con la producción y venta de café bajo su propia marca y una docena de productos orgánicos certificados se posiciona como la empresa con más actividades económicas, y por tanto la más diversificada de la región (ver Tabla 3).

\footnotetext{
${ }^{8}$ Los distintivos $\mathrm{H}$ y M son otorgados por la Secretaría de Turismo. El primero, a las empresas que cumplen con los requisitos establecidos en la norma mexicana NMX-F-605-NORMEX-2018 "Alimentos-Manejo higiénico en el servicio de alimentos preparados". El segundo, a las empresas del sector que cumplen con los requisitos en el marco del Programa de Calidad Moderniza (Secretaría de Turismo, 2015 y 2017). Tesoros de México es un programa de calidad de servicios turísticos de la Secretaría de Turismo federal que certifica hoteles y restaurantes que cumplen con estándares de calidad establecidos por la Asociación Nacional de Tesoros de México, A.C. (2020).

${ }^{9}$ Son cuatro fideicomisos públicos que tienen el carácter de entidades de la Administración Pública Federal, en los que funge como fideicomitente la Secretaría de Hacienda y Crédito Público y como fiduciario el Banco de México, cuyo fin es facilitar el acceso al crédito por medio de operaciones de crédito y descuento, así como el otorgamiento de garantías de crédito a proyectos relacionados con la agricultura, ganadería, avicultura, agroindustria, pesca y otras actividades conexas o afines que se realizan en el medio rural (FIRA, 2020).
}

EntreDiversidades. Revista de Ciencias Sociales y Humanidades, vol. 8, núm. 1 (16), enero-junio 2021. Páginas: 6 - 35 ISSN-e: 2007-7610. https://doi.org/10.31644/ED.V8.N1.2021.A01 


\section{El caso de la Finca Irlanda}

Después de 1989 en el Soconusco, como en otras regiones cafetaleras, algunas fincas impulsaron métodos de producción orgánica como respuesta a las crisis recurrentes del precio de aromático; sin embargo, en el caso de Finca Irlanda el sistema orgánico se introdujo como parte de una filosofía orientada a la conservación de la naturaleza y a satisfacer un mercado que gusta de un café especial. Es decir, se trató de una decisión estratégica distinta a sus vecinos productores de la región que ha hecho que el café se mantenga en el gusto de los consumidores europeos y en la conveniencia comercial de los torrefactores.

La plantación de Irlanda se localiza a 65 kilómetros al norte de Tapachula ${ }^{10}$, Chiapas —a dos horas de viaje—- después de las fincas Nueva Alemania, Maravillas, Génova y Hamburgo; a una altitud de $1140 \mathrm{msnm}$, lo que le permite cumplir con exigentes estándares de calidad y participar en el mercado de especialidades. Su sistema de producción, desde hace medio siglo, se define como biodinámico, en el entendido de que no generan residuos que causen daños al ambiente, sino que los aprovecha para producir abono orgánico o gas butano a partir del tratamiento del agua y de los desperdicios de toda la finca. Desde entonces, la familia Peters, dueños de la finca, estableció cuatro grandes directrices que aún mantienen vigentes contra todo pronóstico: respeto a los árboles, privilegiando las especies endémicas; protección y propagación de la flora y de la fauna silvestre; aprovechamiento de todos los desechos orgánicos; y el resguardo de áreas con vegetación original, manteniendo una reserva natural de 30 hectáreas que representan el 10 por ciento del total de la propiedad.

Esta finca ha influido en las estrategias recientes que emprenden tanto los empresarios cafetaleros como los pequeños productores del Soconusco y cafeticultores de otras regiones. También, ha contribuido en el establecimiento de relaciones comerciales entre las empresas locales y los actores transnacionales (Espinosa, 2018). Por ejemplo, el dueño de la Finca Irlanda vinculó al de la Finca Perú con el torrefactor norteamericano JBR Gourmet Foods Inc. También influyó en la familia Gramlich, que administra las empresas Rancho Alegre y Cuilco, para la transformación de un sistema convencional de producción a uno orgánico en 1989, y a un sistema biodinámico en 1992 (Espinosa, 2018: 181). Esta empresa después decidió no refrendar las certificaciones, pero mantiene el esquema y las prácticas de producción para colocar el cien por ciento de su producción en el mercado nacional con marca propia que define su producto como orgánico.

La plantación es propiedad de la familia Peters desde 1928, año en que fue adquirida por Rodolfo Peters a una persona de origen irlandés (de ahí el nombre de la finca) para heredarla a su hijo Walter Peters Grether, quien logró en 1967 — después de 6 años de trabajo- el primer certificado biodinámico mundial, otorgado por la empresa Demeter Bund de Alemania. Don Walter es el responsable del prestigio y el reconocimiento nacional e internacional que actualmente tiene Irlanda como pionera en producción de café orgánico (sin la utilización de plaguicidas o fertilizantes químicos) y biodinámico (nutrido con compostas y otros biofertilizantes que

\footnotetext{
${ }^{10}$ Se encuentran en esta ciudad las oficinas corporativas de la Finca Irlanda y demás empresas asociadas al Grupo Peters, conformado por Finca Irlanda S.A.P.I. de C.V., Productos Naturales de la Región Maya de Chiapas, S. A. de C. V. (Pronatmaya), las cafeterías Oro Maya Kaffee Haus y la Fundación Peters.
}

EntreDiversidades. Revista de Ciencias Sociales y Humanidades, vol. 8, núm. 1 (16), enero-junio 2021. Páginas: 6 - 35 ISSN-e: 2007-7610. https://doi.org/10.31644/ED.V8.N1.2021.A01 
estimulan la vida del suelo y de las plantas). Comenzó la tarea cuando la práctica común era la agricultura intensiva al amparo de los postulados de la Revolución Verde, que proponía eliminar los árboles de sombra y usar herbicidas, insecticidas y fertilizantes sintéticos para incrementar significativamente la productividad de las tierras.

Conquistar un mercado entonces inexistente con un producto nuevo fue todo un reto. En 1967, Walter Peters logró exportar a Europa el primer embarque de 200 sacos de café orgánico biodinámico. Con esto, no fue únicamente pionero en la producción de un grano libre de agroquímicos, sino en comercializarlo con esas novedosas características. El primer cliente fue la firma Lebensbaum de Alemania, seguida por las compañías Henauer de Suiza y Simon Levelt de Holanda. En 1980, buscando abrir el mercado estadounidense, se enviaron los primeros 100 sacos de café a la firma estadounidense Clean Foods Inc. de California.

Los clientes de Irlanda conocen la calidad de este producto específico, lo que ha asegurado los contratos de compraventa a largo plazo sin depender de las empresas certificadoras, sino del reconocimiento de su proceso. Por ejemplo, la Asociación Suiza de Consumidores para la Promoción de la Agricultura Biodinámica y la compañía suiza Henauer Kaffee reconocen a Irlanda como "uno de los primeros cultivos agrícolas biodinámicos del mundo" (Demeter Konsumenten, 2007). Esta última ofrece el café de la finca como un producto sin mezclar, de la variedad arábiga de la más alta calidad, con certificado Demeter, así como también una versión descafeinada (Kaffi Schopp, 2010).

El café que Henauer Kaffee ofrece con las características de producción biodinámica y certificado Demeter lo obtiene actualmente de dos fincas, Irlanda y otra ubicada en Brasil, Fazenda Camocim (Henauer Kaffee, 2019). La relación comercial entre las dos empresas y el valor que le dan a esa "asociación amistosa y de larga data" se ha desarrollado por más de noventa años. Como parte de esta sociedad y relación de confianza, pagan su café por adelantado, financian estancias de investigadores en la propiedad ${ }^{11} \mathrm{y}$ destinan recursos para la conservación de más de 10000 metros cuadrados de selva tropical (Henauer Kaffee, 2019).

Asimismo, para la firma alemana Lebensbaum la Finca Irlanda representa el proyecto de agricultura orgánica más antiguo del mundo y sostiene que es copropietaria de la finca mediante una sociedad que se dio a partir de ciertas dificultades financieras de la empresa mexicana y la caída en la producción del café debido, entre otros factores, a las afectaciones de la roya (Lebensbaum, 2018). Esta sociedad contempla el apoyo para la renovación de la capacidad de producción de la plantación, así como la mejora de las condiciones de vida de las familias que viven en la propiedad (Lebensbaum, 2018, 2019) ${ }^{12}$.

Aunque el mercado de productos orgánicos ha crecido ante la exigencia de una mayor competitividad, Irlanda no ha pagado una certificación para el mercado estadounidense desde hace siete años, porque está convencida de que goza de un reconocimiento en el mercado, avalado por su larga historia y por ser pionera en el proceso de producción seńalado. Walter Peters afirma

\footnotetext{
${ }^{11}$ Constantemente la finca recibe visitas por motivos académicos. Por sus características ha sido motivo de investigaciones de universidades nacionales y extranjeras interesadas en conocer y estudiar el sistema de producción orgánico-biodinámico y sus resultados en cuanto a la conservación de la flora y la fauna.

${ }^{12}$ Esta sociedad está reconocida en la base de datos de las sociedades mexicanas con inversión extranjera en su capital social, desde el año 2010 (Secretaría de Economía, 2020).
}

EntreDiversidades. Revista de Ciencias Sociales y Humanidades, vol. 8, núm. 1 (16), enero-junio 2021. Páginas: 6 - 35 ISSN-e: 2007-7610. https://doi.org/10.31644/ED.V8.N1.2021.A01 
que la certificación se volvió "un candado que los mercados internacionales imponen" (Espinosa, 2018: 177). Es decir, las fincas son certificadas sin un compromiso verdadero por preservar el medio ambiente, sino por cumplir una exigencia del mercado. En algunos ciclos no ha buscado los sellos porque le ha implicado costos económicos excesivos que ya no están dispuestos a asumir, como hospedar durante semanas a los certificadores, además de todos los trámites.

El fuerte compromiso que tiene la familia Peters con la producción de café biodinámico y con sus clientes no entra en conflicto con la diversificación económica y de mercados. Considera necesario buscar otros mecanismos para sobrellevar la inestabilidad en los precios y lo hace con la prestación de servicios turísticos en el marco del proyecto de La Ruta del Café, con el procesamiento y comercialización de productos agrícolas —algunos con sello orgánico, incluida la parte del café para el mercado nacional - y con la propuesta de franquiciar el modelo de negocio de cafetería boutique: Oro Maya Kaffee Haus, la cual ya cuenta con tres unidades.

A diferencia de otras fincas de la región, Irlanda ha demostrado fehacientemente su sistema de sustentabilidad. Desde comienzos de la década de 1960, sus dueños se han comprometido con el cuidado del medio ambiente, objetivo prioritario antes del interés económico de corto plazo, por lo que su café sigue siendo uno de los más apreciados entre sus clientes de Alemania, Suiza, Holanda, Dinamarca, Inglaterra, Japón y Estados Unidos, al grado de reconocer el origen en sus bolsas y publicar reseñas en sus páginas web con la historia de la finca. Walter Peters ha dedicado su vida a desarrollar tecnologías agrícolas, amigables con el medio ambiente y a difundirlas. Este empresario reinventa el proceso de producción orgánica para impulsar la agricultura biodinámica y compartirla con otros cafetaleros.

\section{Conclusiones}

La perspectiva dominante acerca de la globalización refiere la profundización de la expansión del capitalismo, la reorganización de la producción, la difusión de tecnologías y la profunda interrelación de personas, países y empresas, principalmente a partir de la década de los setenta del siglo XX. Sin embargo, en ocasiones este enfoque no es suficiente para abordar los procesos de configuración de la globalización desde regiones específicas en una perspectiva histórica.

La región Soconusco en Chiapas, al sur de México, se formó a partir del desarrollo de una economía de plantación, con el cacao, hule y café como sus principales productos que, desde fines del siglo XIX, la vincularon más con la economía global que con el espacio estatal y nacional. La producción, transformación y distribución de café ha configurado el territorio, así como su vinculación con el resto del mundo de modo que puede caracterizarse como una región global.

El Estado tuvo un papel central en el desarrollo del capitalismo de la región a partir de generar las condiciones legales para la disponibilidad de tierra y la plantación de café por parte de actores empresariales. El conjunto de relaciones sociales que permitieron la obtención y circulación del café por el mundo, desde el Soconusco, configuró un grupo económico interrelacionado, que no obstante los conflictos y rompimientos de negociaciones que se han presentado, se vinculó de cierta forma (y lo sigue haciendo) con una clase capitalista

EntreDiversidades. Revista de Ciencias Sociales y Humanidades, vol. 8, núm. 1 (16), enero-junio 2021. Páginas: 6 - 35 ISSN-e: 2007-7610. https://doi.org/10.31644/ED.V8.N1.2021.A01 
transnacional, en el sentido que lo plantea Robinson (2014a), es decir, aunque no se trata de un grupo unificado, tiene conciencia de su transnacionalidad.

Mientras se puede hablar de una especie de neocolonización de la región por las corporaciones transnacionales del café (importadoras y torrefactoras), la experiencia analizada muestra una serie de complejas alianzas entre empresarios locales y sus socios de otras latitudes. Es decir, en la fase más reciente de globalización, los empresarios regionales recrearon su relación con la industria del café, de una manera muy diversificada. Un grupo retomó las certificaciones impuestas por los actores dominantes de la industria, otro retó estos estándares y creó sellos específicos al territorio y agroecosistema de las plantaciones de café, y finalmente un tercer grupo diversificó las actividades al interior de la empresa. Resalta con ello una cualidad contingente y heterogénea de la globalización en el sector agroalimentario (Marsden, et al., 2010: 294).

Tales negociaciones heterogéneas y flexibles muestran la configuración de espacios de operación que se imbrican en las tendencias más conocidas de la globalización en la industria del café, es decir, atraviesan sistemas de regulación y relaciones globales. Como parte de esto, fue notable el hecho de que, frente a los requerimientos de producción orgánica, se desencadenó una serie de experiencias diversificadas como fue la exploración que realizaron los empresarios cafetaleros del Soconusco de otras opciones comerciales como el mercado de cafés especiales.

El debate sobre la globalización subraya que la evolución de la economía global no es un proceso lineal. Más específicamente, la globalización no implica el control directo del flujo de recursos y procesos. Por el contrario, contiene una serie de alternativas al control directo que, en última instancia, son beneficiosas para los actores más relevantes. Como la globalización también implica luchas entre grupos en competencia, la búsqueda de equilibrios que sean funcionales para la creación de ganancias es importante. El accionar de los empresarios del café en la región Soconusco de Chiapas, al sur de México, refleja en gran medida estas observaciones teóricas sobre la globalización. Estos empresarios establecieron un sistema en el que los circuitos globales de producción y distribución de café no son la expresión de un simple control corporativo de la producción. Son la extensión de equilibrios que, emergiendo de complejos procesos de interacción, genera beneficios a los principales actores involucrados.

\section{Bibliografía citada}

Alonso, Ramiro (2011). "Nestlé inyectará 15 mdd en Toluca. La inversión será a 10 años en el sector caficultor”. El Universal, [en línea]. Disponible en https://www.pressreader.com/ mexico/el-universal/20110929/282338266615767 (Consultado el 24 de junio de 2020).

Amadeo, Pablo (ed.) (2020). Sopa de Wuhan: pensamiento contemporáneo en tiempos de pandemia. Editorial ASPO. Disponible en : https://drive.google.com/file/d/1tShaH2j5A 9n9cWl6 mhxtaHiGsJSBo5k/view (Consultado el 20 de abril de 2020).

Arrighi, Giovanni (2010). The Long Twentieth Century: Money, Power and the Origins of Our Times. London, United Kingdom: Verso.

EntreDiversidades. Revista de Ciencias Sociales y Humanidades, vol. 8, núm. 1 (16), enero-junio 2021. Páginas: 6 - 35 ISSN-e: 2007-7610. https://doi.org/10.31644/ED.V8.N1.2021.A01 
Asociación Nacional de Tesoros de México, A.C. (2020). Tesoros de México. [en línea]. Disponible en: https://tesorosdemexico.mx/ (Consultado el 20 de mayo de 2020).

Berth, Christiane (2018). Biografias y redes en el comercio del café entre Alemania y América Central 1920-1959. México: Centro de Investigaciones Multidisciplinarias sobre Chiapas y la Frontera Sur, Universidad Nacional Autónoma de México.

Campling, Liam \& Selwyn, Benjamin (2018). Value Chains and the World Economy: Genealogies and Reformulations, in Andreas Nölke and Christian May (eds.), Handbook of the International Political Economy of the Corporation. Northampton, Massachusetts, United States: Edward Elgar Publishing, pp. 416-434. DOI: https://doi. org $/ 10.4337 / 9781785362538$

Chase-Dunn, Christopher (1998). Global Formation. Structure of the World Economy. Lanham, Maryland, United States: Rowan and Littlefield.

Comercializadora e Industrializadora de Productos Chiapanecos (CIP) (s/f). Fincas. [en línea]. Disponible en: http://www.cafecal.com/Fincas.html (Consultado el 24 de junio de 2020).

Cooper, Daniel S. (2006). "Ecological Assessment of Seven Coffee Farms in the Soconusco Region of Chiapas, Mexico". Reporte preparado para Rogers Family Company noviembre de 2006. Disponible en: https://www.researchgate.net/publication/237518741 Ecological assessment of seven coffee farms in the Soconusco region of southeastern Chiapas Mexico (Consultado el 20 de abril de 2020).

Cooper, Daniel S. (2016). "Ecological re-assessment of seven coffee farms in Soconusco, southeastern Chiapas, Mexico.” Reporte preparado para Rogers Family Company en marzo de 2016. Disponible en: https://www.researchgate.net/publication/320841940 Ecological re-assessment of seven coffee farms in Soconusco southeastern Chiapas Mexico 2006-2016 (Consultado el 20 de abril de 2020).

Crouch, Collin (2011). The Strange non-Death of Neoliberalism. Cambridge, United Kingdom: Pluto Press.

Demeter Konsumenten (2007). "Ausgezeichnet: als demeter-produkte des monats" Informationsschrift zur Konsumentenbildung des Verbandes «Demeter Konsumenten» .núm. 6, febrero 2007. [en línea]. Disponible en: https://www.konsumentenverband.ch/ download/pdf/Demeter-Kaffee Irlanda.pdf (Consultado el 15 de junio de 2020).

Diamond, Patrick (2019). The Crisis of Globalization: Democracy, Capitalism and Inequality in the Twenty-First Century. New York, United States of America: I.B. Tauris.

Dicken, Peter (2015). Global Shift. Mapping the Changing Contours of the World Economy. New York, United States of America: Guilford Publications.

Ecoagricultor (s/f). ¿Qué es la Agricultura Biodinámica? [en línea]. Ecoagricultor. Tienda ecológica. Disponible en: https://www.ecoagricultor.com/que-es-la-agricultura-biodinamica/ (Consultado el 15 de marzo de 2020).

ECOM Agroindustrial Corp. (2020). Sustainability Report. [en línea]. Pully, Switzerland: ECOM Agroindustrial Corp. Limited. Disponible en: https://www.ecomtrading.com/ wp-content/uploads/2020/06/ECOM Sustainability Annual Report 2020.pdf (Consultado el 1 de julio de 2020).

EntreDiversidades. Revista de Ciencias Sociales y Humanidades, vol. 8, núm. 1 (16), enero-junio 2021. Páginas: 6 - 35 ISSN-e: 2007-7610. https://doi.org/10.31644/ED.V8.N1.2021.A01 
Espinosa, Manuel Iván (2018). Los empresarios cafetaleros del Soconusco, Chiapas, frente a la globalización. Tesis para obtener el grado de Doctor en Estudios Regionales, Universidad Autónoma de Chiapas. Disponible en: https://www.repositorio.unach.mx/jspui/ handle/123456789/3132

Fideicomisos Instituidos en Relación con la Agricultura (FIRA) (2020). ¿Quiénes somos? [en línea]. Disponible en: https://www.fira.gob.mx/Nd/AcercadeNosotros.jsp (Consultado el 20 de diciembre de 2020).

Fletes, Héctor (2015). “Cadenas de mercancías y dinámicas espaciales. La industria del mango en México", en Sánchez, Julieta (Coord.). Comercio, Organizacionesy Cadenas de Valor. México: Universidad Juárez del Estado de Durango, Institute of Latin American Studies, Columbia University, Prometeo, pp. 97-125. También disponible en https://www.academia.edu/ search?utf8=\%E2\%9C $\% 93 \& \mathrm{q}=$ comercio $\% 2 \mathrm{C}+$ organizaciones $+\mathrm{y}+$ cadenas + de + valor

Green, Jeremy (2019). Is Globalization Over? Cambridge, United Kingdom: Polity Press.

Hanns R. Neumann Stiftung (2019). Our work. [en línea]. HRN Stiftung. Disponible en: https://www.hrnstiftung.org/what-we-do/ (Consultado el 20 de abril de 2020).

Hardt, Michael y Negri, Antonio (2001). Empire. Cambridge, Massachusetts, United States of America: Harvard University Press.

Harvey, David (2003). The New Imperialism. New York, United States of America: Oxford University Press.

Helbig, Carl (1964). El Soconusco y su zona cafetalera en Chiapas. Tuxtla Gutiérrez, Chiapas, México: Instituto de Ciencias y Artes de Chiapas.

Henauer Kaffee (2019). Demeter: Die Finca Irlanda. [en línea] Henauer Kaffee. Disponible en https://henauer-kaffee.ch/ueber-uns/demeter (Consultado el 15 de junio de 2020).

Henderson, Jeffrey, et al. (2002). "Global Production Networks and the Analysis of Economic Development”, Review of International Political Economy, 9 (3), 436-464. Disponible en: DOI: https://doi.org/10.1080/09692290210150842 (Consultado el 29 de mayo de 2020).

Henderson, Thomas P. (2019), "La roya y el futuro del café". Revista Mexicana de Sociología 81(2), pp. 389-416. También disponible en: http://mexicanadesociologia.unam.mx/ index.php/v81n2/323-v81n2a6

Hernández, Juan (2019). "El proceso de la cafeticultura mexicana: una contribución para la toma de decisiones y definición de política pública”, en Bello, Eduardo; Soto, Lorena; Huerta, Graciela; Gómez, Jaime (eds.). Caminar el cafetal. Perspectivas socioambientales del café y su gente. México: El Colegio de la Frontera Sur y Juan Pablos Editor, pp. 427-437.

International Coffee Partners (2019). "Who We Are”. [en línea]. Disponible en: https://www. coffee-partners.org/ (Consultado el 4 de diciembre de 2020).

Kaffi Schopp (2010). "Henauer Kaffee - Neu im Kaffi Schopp Sortiment”. Kaffi Schopp Blog. [en línea]. Disponible en: https:/www.kaffischopp.de/blog/2010/10/08/henauer-kaffeeneu-im-kaffi-schopp-sortiment/ (Consultado el 15 de junio de 2020).

Lebensbaum (2018). Finca Irlanda - Coffee from Mexiko. [en línea]. Lebensbaum. [en línea]. Disponible en: https://www.lebensbaum.com/en/journal/finca-irlanda-coffee-mexiko (Consultado el 15 de junio de 2020).

EntreDiversidades. Revista de Ciencias Sociales y Humanidades, vol. 8, núm. 1 (16), enero-junio 2021. Páginas: 6 - 35 ISSN-e: 2007-7610. https://doi.org/10.31644/ED.V8.N1.2021.A01 
Lebensbaum (2019). Neues von der Finca Irlanda. [en línea]. Lebensbaum Disponible en: https:// www.lebensbaum.com/de/journal/neues-von-der-finca-irlanda (Consultado el 15 de junio de 2020).

Marsden, Terry, et al. (2010). The New Regulation and Governance of Food. Beyond the Food Crisis? Abingdon, United Kingdom: Routledge.

Marx, Karl y Engels, Frederick (1998 [1848]). The Communist Manifesto. London, New York: Verso.

Mercanta (2016). Finca Guadalupe Zaju - Mexico. [en línea] Mercanta. The Coffee Hunters. Disponible en: https://www.coffeehunter.com/the-coffee/finca-guadalupe-zaju/ (Consultado el 10 de junio de 2020).

Nestlé Group (2004). Reporte de Nestlé sobre el café: Las dos caras de la moneda. [en línea]. Le Mont-sur-Lausanne, Suiza: Nestlé S.A. Disponible en: https://empresa.nestle.es/sites/g/ files/pydnoa431/files/es/libreria-documentos/documents/publicaciones/reporte-nestlesobre-el-cafe.pdf (Consultado el 24 de junio de 2020).

Nestlé Group (2011a). Nescafé trabaja con productores de café. [en línea] Nestlé. Disponible en: https://www.nestle.com.mx/media/pressreleases/news2011productores (Consultado el 24 de junio de 2020).

Nestlé Group (2011b). Quality that goes beyond the cup. [en línea] Nestlé. Disponible en: https:// www.nestle.com/brands/coffee/coffeecsv (Consultado el 24 de junio de 2020).

Neumann Kaffee Gruppe (2020). Our Coffee. [en línea]. Exportadora de Café California. Disponible en: https://ecc.com.mx:4488/ (Consultado el: 24 de junio de 2020).

Quiroga, Adriana (2019). "Empresas sociales: medios para transformar los territorios cafetaleros de México", en Bello, Eduardo; Soto, Lorena; Huerta, Graciela; Gómez, Jaime (eds.). Caminar el cafetal. Perspectivas socioambientales del café y su gente. México: El Colegio de la Frontera Sur, Juan Pablos Editor, pp. 337-348.

Renard, María Cristina (1993). El Soconusco: una economía cafetalera. México: Universidad Autónoma de Chapingo.

Renard, María Cristina (1999). Los intersticios de la globalización: un label (Max Havelaar) para los pequeños productores de café. México, D.F., México: Centro de Estudios Mexicanos y Centroamericanos, Embajada del Reino de los Países Bajos, Indígenas de la Sierra Madre de Motozintla (ISMAM)-Coordinadora de Productores de Café del Estado de Oaxaca, Departamento de Sociología Rural y PIDRCAFE de Universidad Autónoma Chapingo. También disponible en: DOI: https://doi.org/10.4000/books.cemca.510

Robinson, William (2014a). Una teoría sobre el capitalismo global. Producción, clase y Estado en un mundo transnacional. México: Siglo XXI.

Robinson, William (2014b). Global Capitalism and the Crisis of Humanity. New York, United States of America: Cambridge University Press.

Rosenberg, Daniel, Mark Eckstein y Chris Brett (2009). Sustainable Trading: Traders as Agents of Sustainability in Coffee and Cocoa Supply Chains. Utrech, The Netherlands: The Dutch Sustainable Trade Initiative (IDH). [en línea]. Disponible en: http://www.bibalex.org/ Search4Dev/files/431935/460335.pdf (Consultado el 20 de mayo de 2020).

EntreDiversidades. Revista de Ciencias Sociales y Humanidades, vol. 8, núm. 1 (16), enero-junio 2021. Páginas: 6 - 35 ISSN-e: 2007-7610. https://doi.org/10.31644/ED.V8.N1.2021.A01 
Rus, Jan (2005). “El café y la recolonización de los Altos de Chiapas. 1892-1910”, en Olivera Mercedes y Palomo Dolores, Chiapas: de la Independencia a la Revolución. México, D. F.: Centro de Investigaciones y Estudios Superiores en Antropología Social y Consejo de Ciencia y Tecnología del Estado de Chiapas. pp. 253- 287.

San Francisco Bay Coffee (2020). Our practice. [en línea] San Francisco Bay Coffee. Disponible en: https://sfbaycoffee.com/pages/our-practice-1 (Consultado el 20 de abril de 2020).

Sánchez, Karina (2016). Intelectuales indigenas como protagonistas de un proceso de autogestión. México: Instituto de Investigaciones Sociológicas, Universidad Benito Juárez de Oaxaca y Juan Pablos Editor.

Sassen, Saskia (1998). Globalization and its Discontents. New York, United States of America: The New Press.

Secretaría de Agricutura, Ganadería, Desarrollo Rural, Pesca y Alimentación (SAGARPA) (2018). Padrón Nacional Cafetalero.

Secretaría de Economía (2020). Registro Nacional de Inversiones Extranjeras (RNIE) Base de datos [en línea]. Disponible en: https://datos.gob.mx/busca/dataset/registro-nacional-deinversiones-extranjeras-rnie (Consultado el 5 de mayo de 2020).

Secretaría de Turismo (2015). Programa Manejo Higiénico de los Alimentos, Distintivo H. [en línea]. Disponible en: https://www.gob.mx/sectur/acciones-y-programas/programamanejo-higienico-de-los-alimentos-distintivo-h (Consultado el 20 de mayo de 2020).

Secretaría de Turismo (2017). Programa de Calidad Moderniza. [en línea]. Disponible en: https://www.gob.mx/sectur/acciones-y-programas/programa-de-calidad-moderniza (Consultado el: 20 de mayo de 2020).

Servicio de Información Agroalimentaria y Pesquera (SIAP) (2020). Anuario Estadístico de la Producción Agricola. [en línea]. Disponible en: https://nube.siap.gob.mx/cierreagricola/ (Consultado el 24 de agosto de 2020).

Sklair, Leslie (2001). The Transnational Capitalist Class. Oxford, United Kingdom: Blackwell. Spenser, Daniela (1988). "Los inicios del cultivo de café en Soconusco y la inmigración extranjera", en Brigida von Mentz, Verena Radkau, Daniela Spenser y Ricardo Pérez Montfort, Los empresarios alemanes, el tercer reich y la oposición de derecha a Cárdenas. México: Centro de Investigaciones y Estudios Superiores en Antropología Social, pp. 61-88.

Streeck, Wolfgang (2014). Global Political Economy and the Modern State System. Leiden, Holand: Brill.

Streeck, Wolfgang (2016). How Will Capitalism End? London, United Kingdom: Verso.

Tashakkori, Abbas y Teddlie, Charles (2010). Handbook of mixed methods in social and behavioral research. Second Edition. Thousand Oaks, California, United States of America: Sage.

Venegas, Andrea, Lorena Soto, Obeimar Balente y Guadalupe Álvarez (2020). “Transformaciones de la caficultura en Chiapas: un análisis de las crisis desde la perspectiva del ciclo de renovación adaptativa". Sociedad y Ambiente, 23, pp. 1-31. DOI: https://doi. org/10.31840/sya.vi23.2188 (Consultado el 20 de diciembre de 2020).

EntreDiversidades. Revista de Ciencias Sociales y Humanidades, vol. 8, núm. 1 (16), enero-junio 2021. Páginas: 6 - 35 ISSN-e: 2007-7610. https://doi.org/10.31644/ED.V8.N1.2021.A01 
Manuel Iván Espinosa Gallegos

Héctor B. Fletes Ocón

Alessandro Bonanno
Contendiendo en la globalización. Los empresarios cafetaleros del Soconusco...

Zamora, Carla, Angélica Pérez y Pablo Picazzo (2019). “Acción colectiva y producción cafetalera. El caso de la cooperativa Maya Vinic en Chiapas”, en Bello, Eduardo; Soto, Lorena; Huerta, Graciela; Gómez, Jaime (eds.). Caminar el cafetal. Perspectivas socioambientales del café y su gente. México: El Colegio de la Frontera Sur, Juan Pablos Editor, pp. 377-386.

\section{Entrevistas}

Espinosa, Iván (2011). Entrevista a Eduardo Bracamontes Gris, finca Perú-Paris, Tapachula, Chiapas [Comunicación personal]. 25 de junio de 2011.

Espinosa, Iván (2011). Entrevista a Tomas Edelmann, finca Hamburgo, Tapachula, Chiapas. [Comunicación personal]. 13 de junio de 2011. 